Please do not remove this page

RMIT

UNIVERSITY

\title{
Macrolactam analogues of macrolide natural products
}

Hugel, Helmut; Smith, Andrew; Rizzacasa, M

https://researchrepository.rmit.edu.au/esploro/outputs/9921860363401341/filesAndLinks?institution=61RMIT_INST\&index=null

Hugel, H., Smith, A., \& Rizzacasa, M. (2016). Macrolactam analogues of macrolide natural products. Organic and Biomolecular Chemistry, 14(48), 11301-11316. https://doi.org/10.1039/c6ob02149b Document Version: Accepted Manuscript

Published Version: https://doi.org/10.1039/c6ob02149b

Repository homepage: https://researchrepository.rmit.edu.au

This journal is (c) The Royal Society of Chemistry 2016

Downloaded On 2023/04/27 00:12:20 +1000 
Thank you for downloading this document from the RMIT Research Repository.

The RMIT Research Repository is an open access database showcasing the research outputs of RMIT University researchers.

RMIT Research Repository: http://researchbank.rmit.edu.au/

\section{Citation:}

Hugel, H, Smith, A and Rizzacasa, M 2016, 'Macrolactam analogues of macrolide natural products', Organic and Biomolecular Chemistry, vol. 14, no. 48, pp. 11301-11316.

See this record in the RMIT Research Repository at:

https://researchbank.rmit.edu.au/view/rmit:43558

Version: Accepted Manuscript

Copyright Statement:

(C) This journal is () The Royal Society of Chemistry 2016

\section{Link to Published Version:}

https://dx.doi.org/10.1039/c6ob02149b 
This article can be cited before page numbers have been issued, to do this please use: M. A. Rizzacasa, H. Hügel and A. T. Smith, Org. Biomol. Chem., 2016, DOI: 10.1039/C6OB02149B.

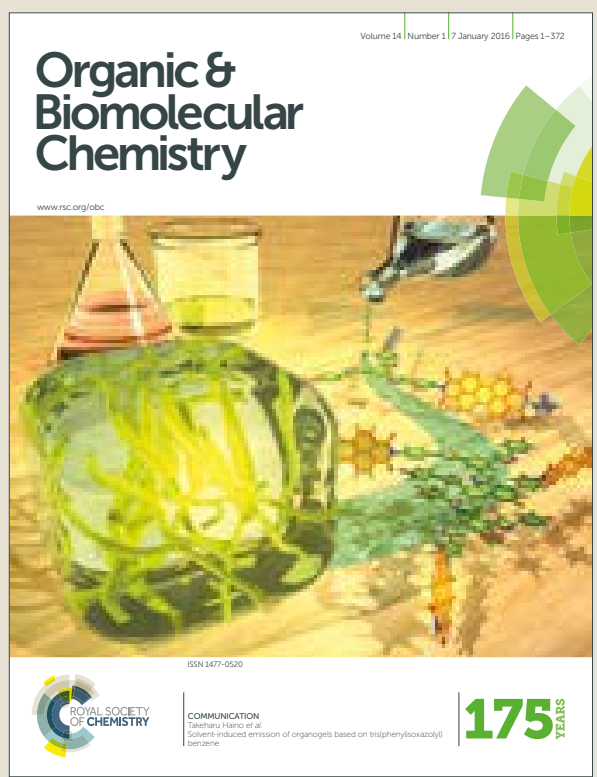

This is an Accepted Manuscript, which has been through the Royal Society of Chemistry peer review process and has been accepted for publication.

Accepted Manuscripts are published online shortly after acceptance, before technical editing, formatting and proof reading. Using this free service, authors can make their results available to the community, in citable form, before we publish the edited article. We will replace this Accepted Manuscript with the edited and formatted Advance Article as soon as it is available.

You can find more information about Accepted Manuscripts in the author guidelines.

Please note that technical editing may introduce minor changes to the text and/or graphics, which may alter content. The journal's standard Terms \& Conditions and the ethical guidelines, outlined in our author and reviewer resource centre, still apply. In no event shall the Royal Society of Chemistry be held responsible for any errors or omissions in this Accepted Manuscript or any consequences arising from the use of any information it contains. 


\title{
Macrolactam analogues of macrolide natural products
}

Helmut M. Hügel, ${ }^{1 *}$ Andrew T. Smith, ${ }^{2}$ Mark A. Rizzacasa ${ }^{3 *}$

${ }^{1}$ School of Science \& Biomedical and Health Innovations Enabling Capability Platform, RMIT University, GPO Box 2476 Melbourne VIC 3001 Australia.

${ }^{2}$ Griffith Sciences, Gold Coast campus, Griffith University, QLD 4222, Australia.

${ }^{3}$ School of Chemistry, the Bio21 Institute, The University of Melbourne, VIC 3010, Australia.

*Corresponding authors, Tel.: +61 39925 2626, +61 383442397.

E-mail addresses: helmut.hugel@rmit.edu.au,masr@unimelb.edu.au

\begin{abstract}
The chemical modifications of macrolide natural products into $a z a$ - or lactam analogues is a strategy employed to improve their metabolic stability and biological activity. The methods for the synthesis of several lactam analogues of macrolide natural products is highlighted and aspects of their biological properties presented.
\end{abstract}

Keywords: macrolactams, aza-epothilone B, 15-aza-salicylihalamide A, migrastatin lactam, radicicol macrolactams

\section{Introduction}

The utilization of biologically active heterocyclic macrocycles in Nature is a reflection of their efficacy and benefit to biological processes. One drug analysis ${ }^{1}$ has revealed that $59 \%$ of smallmolecule drugs contain a ring-nitrogen and most of the approved nitrogen macrocycles are natural products or derivatives of natural products. The major liabilities of macrocyclic natural products ${ }^{2}$ are in vivo instability and significant toxic side effects. In this regard nitrogen or aza-analogues (lactams) often display advantageous properties such as improved reactivity, aqueous solubility, bioavailability, metabolic stability and often also reduced toxicity.
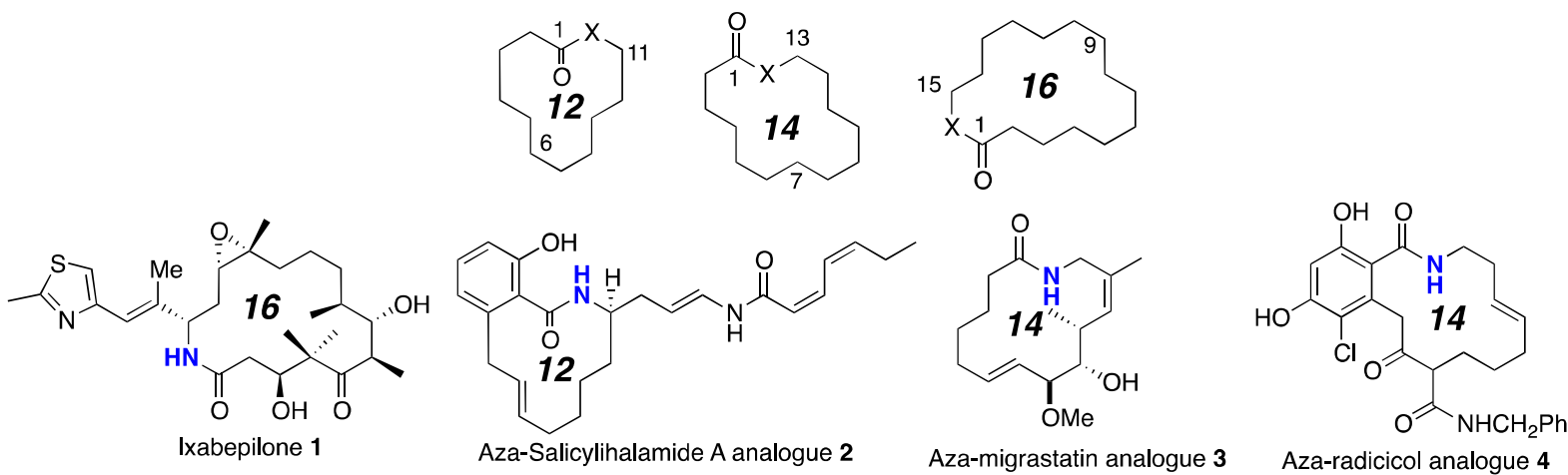

Figure 1. Selected $a z a$ analogues of macrolide natural products.

Macrolide natural products ${ }^{3,4}$ with 12,14 , or 16 membered rings and their semisynthetic derivatives are important clinically relevant compounds predominantly used for the treatment of various types of cancer. ${ }^{5}$ Macrolactams are easily synthesized and offer access to multiple analogues with chemical and enzymatic stability ${ }^{6}$ as well as desirable biological properties. In this short review article, the synthesis and biological activity of some key examples of lactam analogues of 12,14 , and 16 membered macrolides in which only the oxygen atom is substituted by nitrogen in the macrocycle are presented. Examples of aza modified macrolides include the 16-membered 15$a z a$-epothilone B or ixabepilone (1), the most successful lactam modified macrolide which has been approved for the treatment of aggressive metastatic taxol resistant breast cancer, ${ }^{7}$ the 12 -membered 
$a z a$-salicylihalamide analogue $2,{ }^{8}$ the 14 -membered $a z a$-migrastatin ${ }^{9}$ analogue $\mathbf{3}$, and the 14 membered aza-radicicol analogue 4 (Figure 1). ${ }^{10}$

\section{5-Aza-epothilone B [Ixabepilone] (1)}

The epothilones A (6) and B (5) (Figure 2) are members of a group of 16-membered bacterial macrolides originally identified ${ }^{11}$ as secondary metabolites produced by the soil-dwelling myxobacterium Sorangium cellulosum (strain So ce90) which possesses the largest bacterial genome sequenced to date ${ }^{12}(13,033,779$ base pairs). Interest in the epothilones increased when it was discovered in 1995 that they possess potent tubulin binding properties, rivaling taxol in killing dividing cells by inducing tubulin polymerization and enhancing microtubule stability. ${ }^{13}$ Epothilone B (5) shares the same binding site as taxoids, ${ }^{7}$ however their mode of binding within the binding pocket is distinctive. ${ }^{14}$ In addition to epothilone A and B, a diverse number of natural epothilone compounds have been isolated from the same myxobacterium. ${ }^{15}$ Epothilone B (5) was more potent than paclitaxel in inhibiting cell growth. ${ }^{16}$

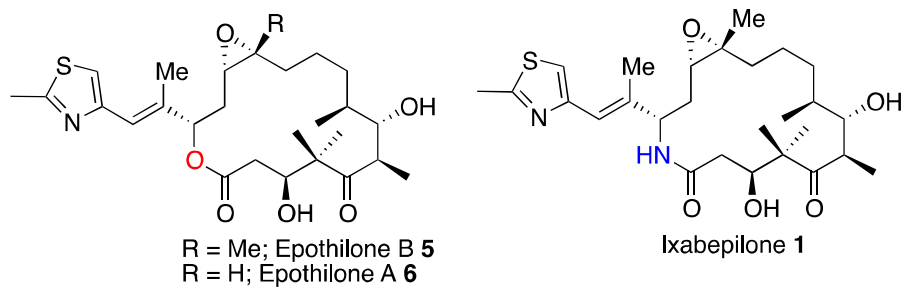

\begin{tabular}{|c|c|c|c|}
\hline \hline Compound & $\begin{array}{c}\text { Efficacy } \\
\text { (LCK) }\end{array}$ & $\begin{array}{c}\mathbf{I C}_{\mathbf{5 0}} \\
(\mathbf{n M )}\end{array}$ & $\begin{array}{c}\text { PPB } \\
(\mathbf{\%})\end{array}$ \\
\hline \hline $\mathbf{6}$ & 0.1 & 4.25 & 76.6 \\
\hline $\mathbf{5}$ & 0.4 & 0.41 & 92.0 \\
\hline $\mathbf{1}$ & 2.1 & 2.60 & 79.4 \\
\hline
\end{tabular}

Figure 2. Selected biological for ixabepilone (1), epothilone B (5) and epothilone A (6) $\left(\mathrm{LCK}=\log \text { cell kill and } \mathrm{IC}_{50} \text { Pat-7 ovarian carcinoma model; PPB }=\text { Plasma protein binding }\right)^{13 \mathrm{c}}$

Intensive chemical analogue synthesis unveiled structure activity relationships ${ }^{17}$ for epothilone B (5). Fortunately, it was quickly recognized that the lactone group is vulnerable to hydrolytic cleavage by esterases which may account for the short half-life of epothilones in the early animal studies. ${ }^{18}$ Further studies resulted in several lead-structures for the discovery of clinical candidates for cancer treatment. ${ }^{17}$ The lactam 15-aza-epothilone B (1) (ixabepilone) ${ }^{19}$ was identified as a potent analogue of epothilone B (5) (Figure 2) and this compound showed high potency against ovarian cancer $\left(\mathrm{IC}_{50}=2.6 \mathrm{nM}\right)$ and leukemia cell lines $\left(\mathrm{CCRF}-\mathrm{CEM}\right.$ : $\left.\mathrm{IC}_{50}=2.1 \mathrm{nM}\right)$ comparable to that for epothilone B (5) $\left(\mathrm{IC}_{50}=0.41 \mathrm{nM}\right)$ but was less toxic. Macrolactam 1 was only $\square 10$-fold lower in activity when compared with epothilone B (5) but also more importantly displayed a 50fold decrease in cytotoxicity. ${ }^{13 a}$ In 2007, ixabepilone (1) by Bristol-Myers Squibb (marketed as Ixempra), was approved by the FDA for the treatment of aggressive metastatic taxol resistant breast cancer. $^{7}$ Key to its success as a cancer therapeutic agent is the fact that the lactam had better metabolic stability (less prone to hydrolysis). Ixabepilone (1) had a metabolic hydrolysis rate [mouse S9 liver fraction: $0.01 \mathrm{nmol} /(\mathrm{min} \mathrm{mg})] 100$ times slower than epothilone $\mathrm{B}(\mathbf{6})$ [1.02 $\mathrm{nmol} /(\mathrm{min} \mathrm{mg})]{ }^{13 \mathrm{c}}$ In addition, ixabepilone has increased water solubility, reducing the use of formulation agent such as cremophor (polyethoxylated castor oil) which can cause allergic reactions in some patients.

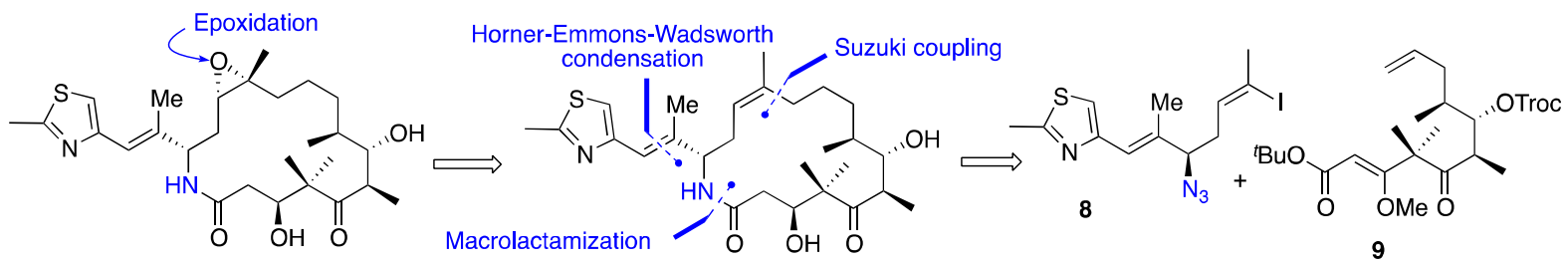

Ixabepilone 1

12,13-Desoxy-15-aza-epothilone B (aza-dEpoB) 7

Scheme 1. Retrosynthetic analysis and key bond connections of ixabepilone (1)

The convergent retrosynthetic strategy for the first total synthesis of ixabepilone (1) is depicted in Scheme 1 and this was utilised by Danishefsky and coworkers. ${ }^{20,21}$ The key transformations involved a late stage epoxidation and a Suzuki coupling and subsequent macrolactamisation to form 
the macrolactam 12,13-desoxy-15-aza-epothilone B (aza-dEpoB) (7). This led to the two precursors vinyl iodide 8 and $\beta, \delta$-diketoester 9.

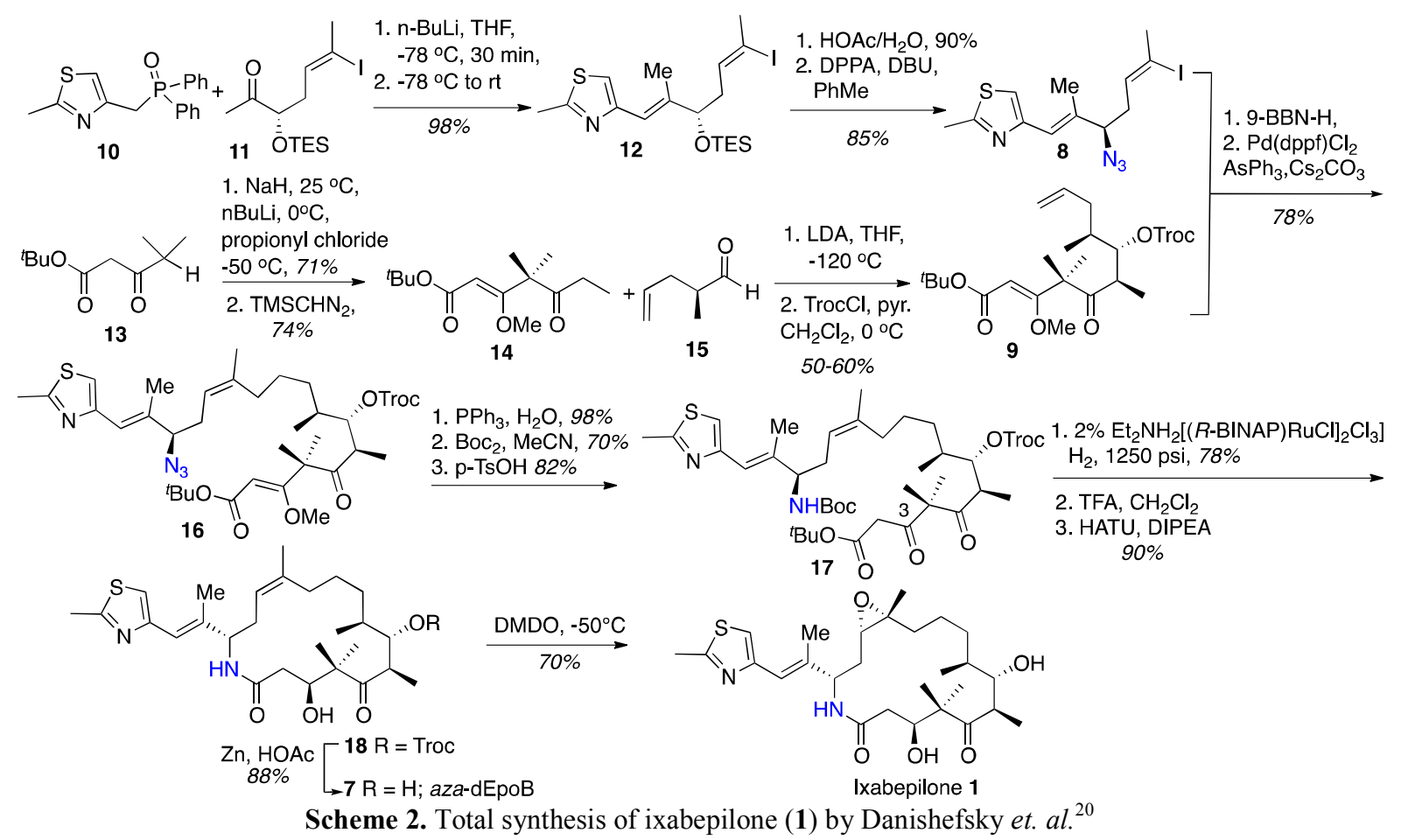

The triethylsilyl protected vinyl iodide $\mathbf{1 2}$ was formed in 98\% yield via a Horner-Emmons type condensation with the readily prepared phosphine oxide $\mathbf{1 0}$ and ketone $\mathbf{1 1}$ (Scheme 2). Deprotection of the TES ether gave an alcohol that was converted into the azide $\mathbf{8}$ by a Mitsunobu reaction. Acylation of $\beta$-ketoester 13 followed by methylation gave enol ether 14. Aldol coupling of the enolate derived from 14 with $S$-2-methyl-4-pentenal 15 and protection as the trichloroethyl carbonate ester (Troc) then afforded adduct 9. The Pd-catalyzed Suzuki cross-coupling reaction of in situ prepared B-alkyl-9-BBN derivative of $\mathbf{9}$ with the azido vinyl iodide $\mathbf{8}$ delivered the corresponding cis-olefin $\mathbf{1 6}$ in $78 \%$ yield. A Staudinger reduction of azide $\mathbf{1 6}$ to the amine, primary amine protection and enol hydrolysis gave carbamate 17. The subsequent asymmetric reduction of C3 carbonyl group was optimized with a modified Noyori catalyst ${ }^{22}$ and yielded a single C3hydroxy diastereoisomer in $78 \%$ yield. Exposure to trifluoroacetic acid deprotected both Boc group and tert-butyl ester and macrolactamisation of the resultant amino acid with HATU in dichloromethane gave macrolactam 18 in $90 \%$ yield. The 07 Troc protecting group was removed in $88 \%$ yield by sonication of 18 in acetic acid and zinc dust to afford $a z a-\mathrm{dEpoB}$ (7), and epoxidation of the $\mathrm{C} 12-13$ (Z)-alkene with 2,2-dimethyldioxirane at $-50{ }^{\circ} \mathrm{C}$ provided a $70 \%$ yield of 15 -azaepothilone B (1) as a single diastereoisomer. Both ixabepilone (1) and Aza-dEpoB (7) showed potent activity against human leukemia cells lines (CCRF-CEM) with 1 slightly being more active $\left(\mathrm{IC}_{50}=2.1\right.$ and $9.5 \mathrm{nM}$, respectively).

Ixabepilone (1) can also be semi-synthesized from epothilone B (5) and this is close to how the material is produced on a large scale for clinical use (Scheme 3). ${ }^{19}$ Remarkably, macrolide ring opening of epothilone B (5) mediated with $\mathrm{Pd}\left(\mathrm{PPh}_{3}\right)_{4}$ gave the $\pi$-allylpalladium complex 19 that could be intercepted by an azide nucleophile. The resultant allylic azide $\mathbf{2 0}$ was then reduced to the amine 21 and cyclized to yield the lactam macrolide 1. Since the natural product epothilone B (5) can be produced in quantity through optimized bacterial fermentation, ${ }^{23}$ this one-pot three-step transformation [20-25\% overall yield] enables ready access to ixabepilone (1). 


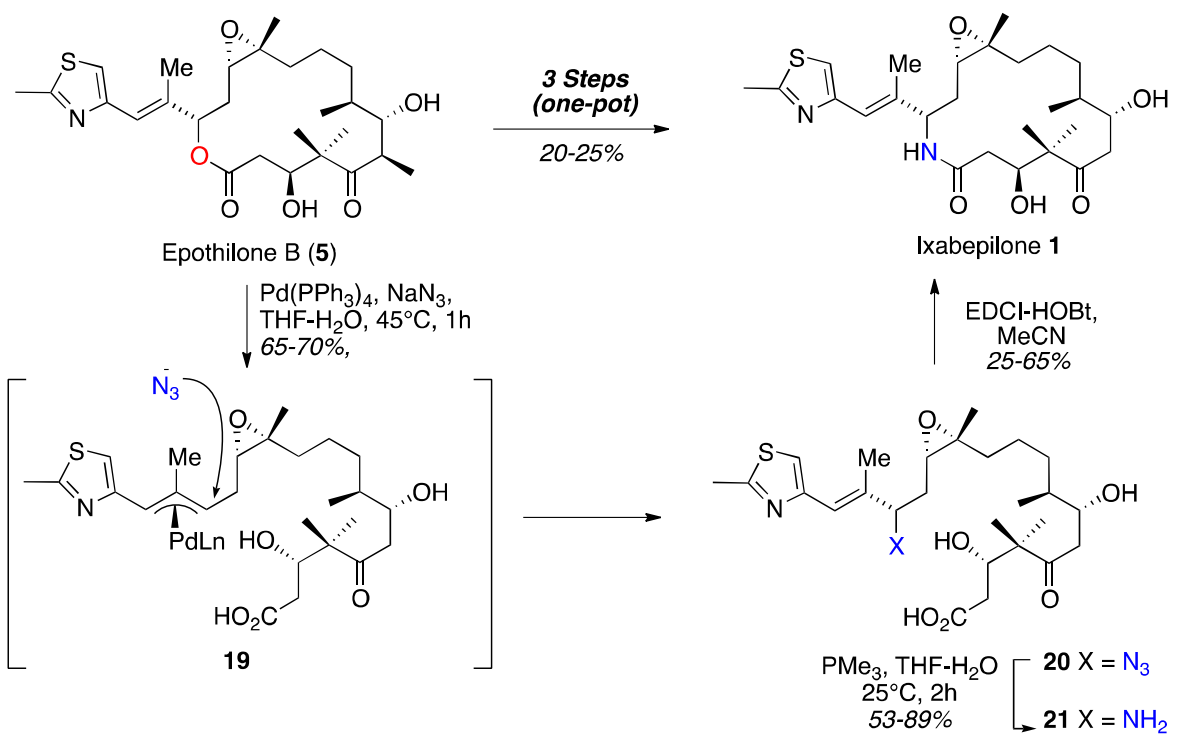

Scheme 3. Semisynthesis of ixabepilone (1) from epothilone B (5). ${ }^{19}$

Molecular energy calculations conducted on epothilone B and ixabepilone ${ }^{24}$ using the MP2//B3LYP method found that the C10-C11-C12-O12 torsion angle directs the exo (epoxide out of macrocycle) and endo (epoxide into macrocycle) conformations of the macrocycle. Importantly, the macrocycles include either two intramolecular hydrogen bonds for epothilone B (5) or three for ixabepilone (1) that accounts for the ring conformations for both lactone/lactam structures. Epothilone B (5) prefers to adopt the compact exo conformation 5ex (Figure 3), as a consequence of the short, near-linear hydrogen bonding between the 3-hydroxyl group and the side-chain thiazole $\mathrm{N}$ atom, and from the 7-hydroxyl to the $\mathrm{C} 5$-ketone that contribute to the total macrolide conformation energy. In contrast, the macrocyclic hydrogen bonding involving the amide group facilitates ixabepilone (1) to exist as competitive mixtures of exo (1ex) and endo (1en) conformers enabling the slightly less stable endo conformer to energetically compete for the taxol binding site. The endo-ixabepilone (1en) conformer thus has cooperative hydrogen bonding between the amide $\mathrm{NH}$, the 3-hydroxyl, and the epoxide. This illustrates that the lactone to lactam change induces significant conformational flexibility within the macrocyclic structure offering more hydrogen bonding patterns and conformational diversity relative to the natural macrolide. This conformational mobility may also contribute to low plasma protein binding observed (see Figure 2) for ixabepilone (1) which could result in better in vivo efficacy.

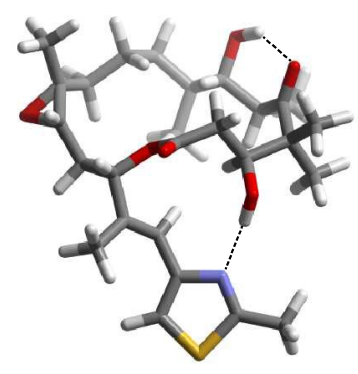

exo-Epothilone B (5ex)

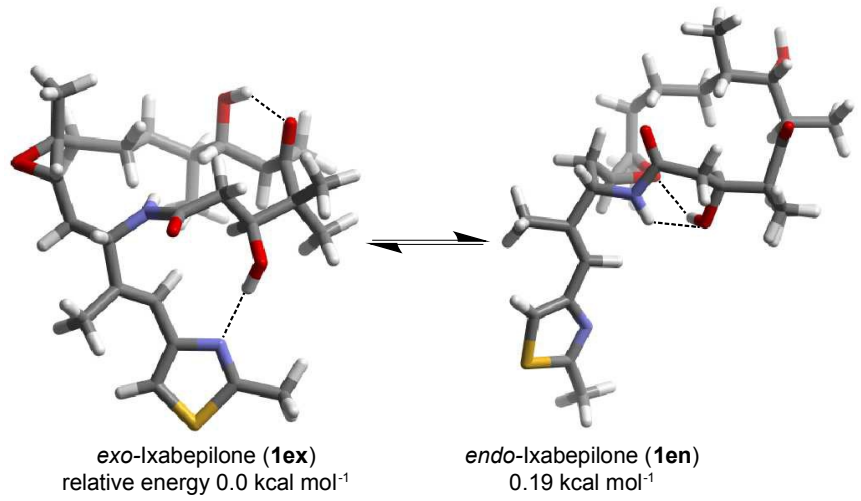

Figure 3. Low energy conformers of exo-epothilone B (5ex) and exo and endo-ixabepilone (1) with critical H-bonds indicated (reproduced from SI data: see Lozynski ${ }^{24}$ )

The electron crystallography structure of epothilone A (6) bound to zinc-stabilized $\alpha, \beta$-tubulin was determined $^{14}$ to a resolution of $2.89 \AA$ and this, along with NMR based conformational analysis, revealed that the bound conformation of $\mathbf{6}$ has the epoxide in the endo orientation (Figure 
4A). Key interactions with Arg276, Thr274 and Arg282 were present along with a H-bond between the thiazole nitrogen atom and His227. As shown in the overlay (Figure 4B), the conformation of bound epothilone A (6) is very close to that the calculated conformer of ixabepilone (1en) above and this may provide an explanation as to why that the macrolactam analogue $\mathbf{1}$ can effectively bind.

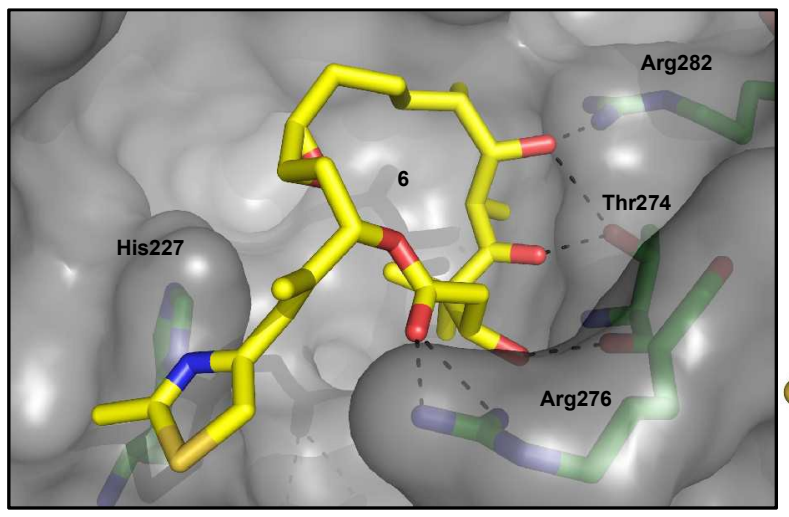

A

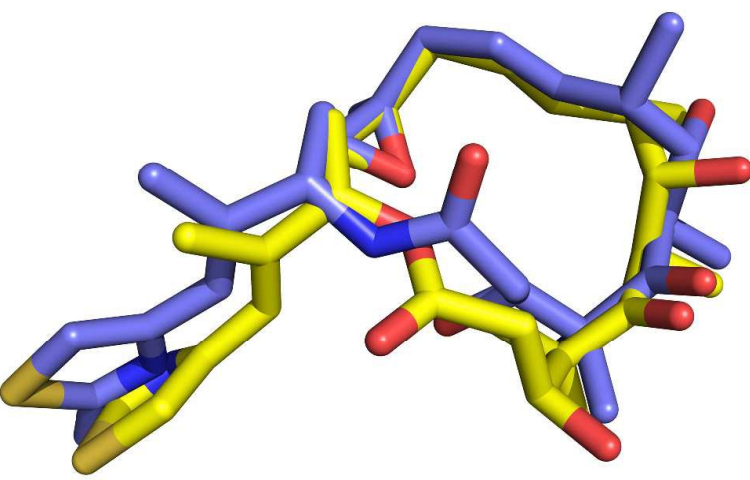

B

Figure 4. (A) Surface map of epothilone A (6) (yellow C atoms) bound to zinc-stabilized two-dimensional crystals of tubulin showing H-bonds as dashed black lines (produced from electron crystallography structure from PDB code 1tvk see Nettles et. al. ${ }^{14}$ ).

(B) Overlay of bound $\mathbf{6}$ (yellow $\mathrm{C}$ atoms) and calculated endo conformer of ixabepilone (1en) ${ }^{24}$ (blue $\mathrm{C}$ atoms)

\section{2,13-desoxy-15-Aza-epothilone A (22)}

A total synthesis of the 12,13-desoxy-aza-epothilone A analogue $\mathbf{2 2}$ has been reported by Schinzer and co-workers ${ }^{25}$ as shown in Scheme 4. Wittig coupling of ylide $\mathbf{2 3}$ and ketone $\mathbf{2 4}$ gave the diene $\mathbf{2 5}$ in high yield after removal of the Boc group. The acid coupling partner $\mathbf{2 8}$ was synthesized from ketone $\mathbf{2 6}$ and aldehyde $\mathbf{2 7}$ via aldol condensation followed by acetal hydrolysis, protection and oxidation. Coupling of amine 25 and acid 28 proceeded in good yields using benzotriazol-1-yl-oxytripyrrolidinophosphonium hexafluorophosphate (pyBOP) to afforded diene 29. RCM using Grubbs I catalyst gave the macrocycle $\mathbf{3 0}$ along with the $E$-isomer as a 1:1 mixture and separation followed by deprotection of the TBS ethers afforded 12,13-desoxy-aza-epothilone A 22 which was active against human epidermoid cancer cell lines KB-31 and KB-8511 $\left(\mathrm{IC}_{50}=464\right.$ and $285 \mathrm{nM}$ respectively) but was less active than ixabepilone (1) indicating the importance of the epoxide. Compound 22 also induced tubulin polymerization at $26 \%$ that measured for epothilone B $(\mathbf{5}){ }^{25}$

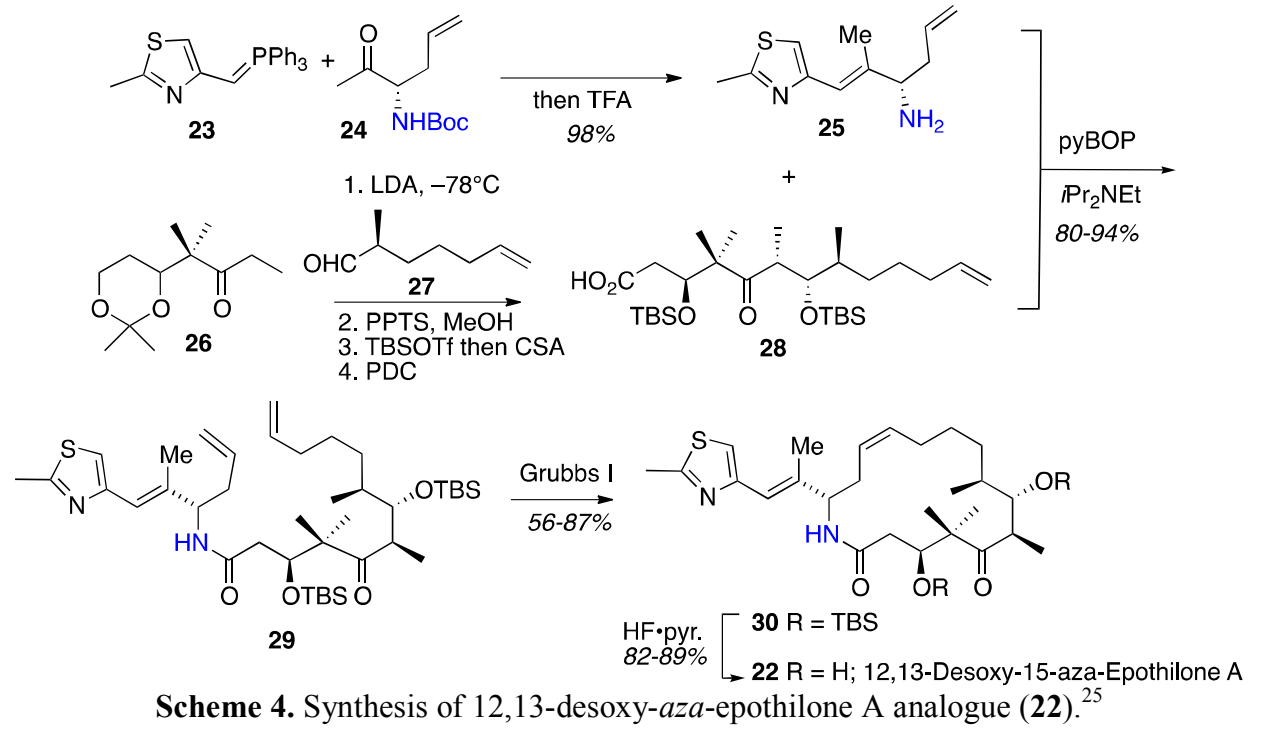




\section{5-Aza-salicylihalamide analogue 2}

The salicylate enamide macrolide natural products shown in Figure 5 are potent antitumor compounds and mammalian vacuolar type proton ATPase (V-ATPase) inhibitors. ${ }^{26}$ Inhibition of these proton pumps eventually leads to cell death via apoptosis. Salicylihalamide A (31) was isolated $^{27}$ from a sponge of the genus Haliclona and is a novel highly cytotoxic macrolide. The myxobacteria metabolite apicularen $\mathrm{A}^{28}(\mathbf{3 2})$ is a potent cyctotoxin against several human tumor cell lines (cervical $\mathrm{IC}_{50} 0.4 \mathrm{ngmL}^{-1}$; kidney $\mathrm{IC}_{50} 0.3 \mathrm{ngmL}^{-1}$ lung $\mathrm{IC}_{50} 0.1 \mathrm{ngmL}^{-1}$, prostate $\mathrm{IC}_{50} 0.5$ ngmL $^{-1}$ ) and contains the same novel secondary enamide functionality ${ }^{29}$ as found in salicylihalamide A (31). ${ }^{27}$ It also possesses a similar benzolactone with an internal 9,13-transtetrahydropyran ring and shows highly effective growth inhibition of several human tumor cell lines.

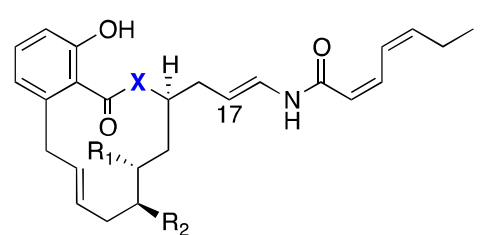

$\mathrm{X}=\mathrm{O} ; \mathrm{R}^{1}=\mathrm{OH} ; \mathrm{R}^{2}=\mathrm{Me} ;$ Salicylihalamide $\mathrm{A} \mathbf{3 1}$ $\mathrm{NCl} 60$ cell line average $\mathrm{GI}_{50}=15 \mathrm{nM}$ $\mathrm{X}=\mathrm{O} ; \mathrm{R}^{1}=\mathrm{R}^{2}=\mathrm{H}$; Salicylihalamide $\mathrm{A}$ analogue $3 \mathbf{3}$

$\mathrm{X}=\mathrm{NH} ; \mathrm{R}^{1}=\mathrm{R}^{2}=\mathrm{H} ; 15$-aza-Salicylihalamide $A$ analogue 2

Figure 5. Salicylihalamide A (31) and analogues 33 and $\mathbf{2}$ and apicularen A (32).

The simplified salicylihalmide analogue $\mathbf{3 3}$ also showed potent activity against human tumor cells lines [SF268 (CNS glioma), GI $0.27 \mu \mathrm{M}$; DU-145 (prostate cancer) $2.12 \mu \mathrm{M}$ ]. ${ }^{30}$ The discovery and effectiveness of the potent ixabepilone (1) that was found to exhibit a better therapeutic range than epothilone $\mathrm{B}$ inspired the research into modification of the salicylihalamide (31) 12-membered macrolactone into $a z a$-salicylihalamide A analogue 2.

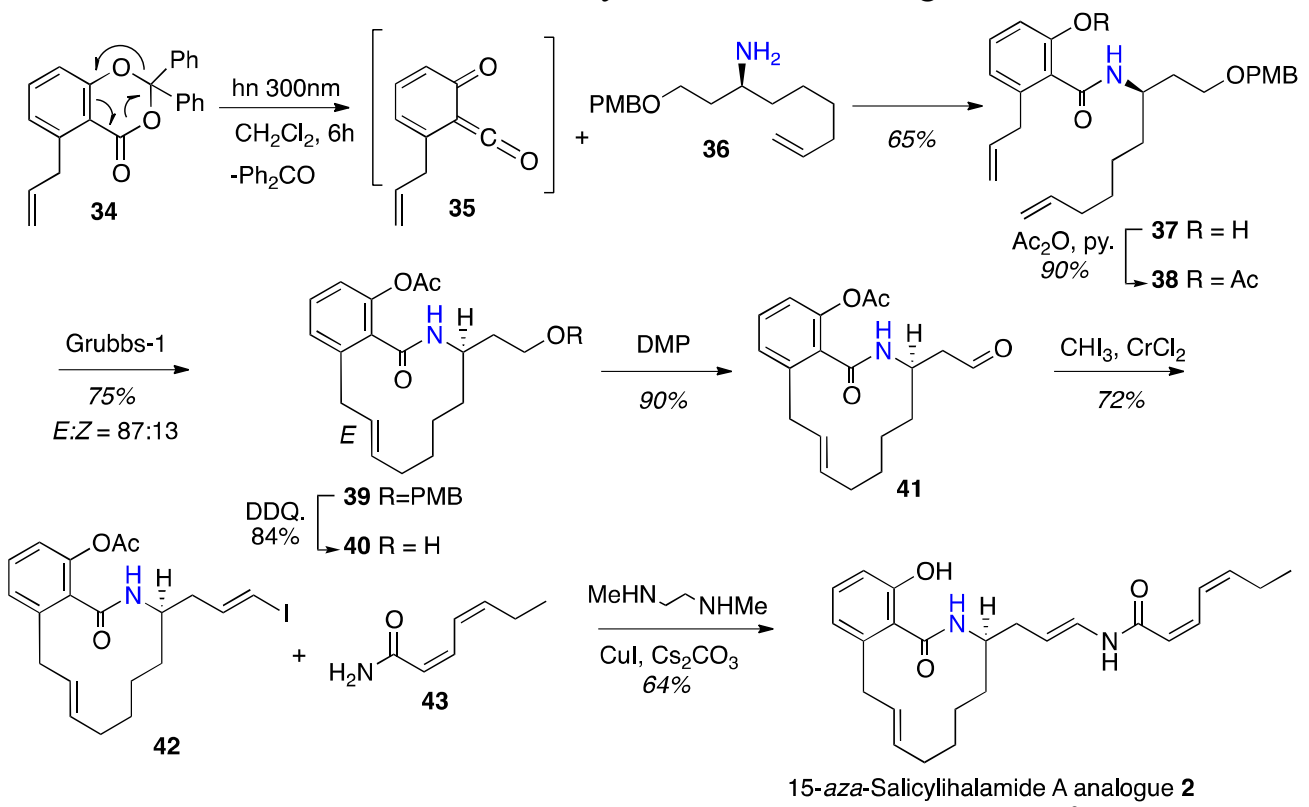

Scheme 5. Synthesis of 15-aza-salicylihalamide A analogue (2). ${ }^{8}$

The synthesis of the simplified 15-aza-salicylihalamide A analogue 2 shown in Scheme 5 involved the following key synthesis steps that are all scalable. ${ }^{8}$ To form the amide, a photochemical acylation reaction ${ }^{31}$ was utilised in which the quinoketene intermediate $\mathbf{3 5}$, formed from photolysis of 1,3-dioxanolone 34, was captured by the optically pure amine $\mathbf{3 6}$ to yield the diene 37 in $65 \%$ yield. This method of amide formation was far superior to alternatives involving traditional benzoic acid-amine cross couplings. The highest $E$ selectivity in the ring closing 
metathesis was observed using Grubbs $1^{\text {st }}$ generation catalyst on the acetate protected diene 38 which gave the lactam 39 in $75 \%$ yield. Other protecting groups, such as methyl and silyl based ones gave inferior $E: Z$ selectivities in the RCM reaction. PMB group removal gave alcohol $\mathbf{4 0}$ and oxidation provided aldehyde 41, the structure of which was confirmed by X-ray crystallography. A Takai homologation gave the vinyl iodide $\mathbf{4 2}$. The final step involved the copper mediated cross coupling $^{32}$ of iodide $\mathbf{4 2}$ with dienamide $\mathbf{4 3}$ which resulted in the CuI catalyzed attachment of enamide side chain giving the aza-salicyliamide analogue 2 in $64 \%$ yield.

The 15- $A z a$-salicylihalamide A analogue 2 showed potent activity ${ }^{8}$ against several leukemia cell lines and this was compared to the readily available V-ATP-ase inhibitor bafilomycin A1 (44) $)^{33}$ since salicylihalamide (31) was not available (Figure 6). Analogue 2 was 10 times less active on average than bafilomycin A1 (44) but in a linear relationship, suggesting analogue 2 has the same mode of action.

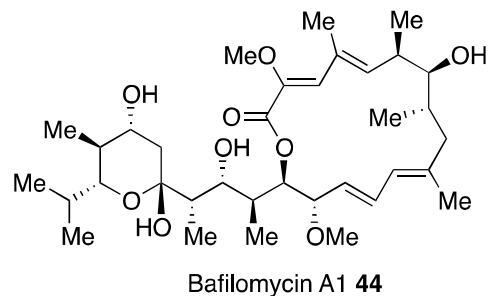

\begin{tabular}{|c|c|c|}
\hline \hline Cell line & $\begin{array}{c}A z a-\text { analogue 2 } \\
\mathbf{I C}_{\mathbf{5 0}}(\mathbf{n M})\end{array}$ & $\begin{array}{c}\text { Bafilomycin A1 } \\
(\mathbf{4 4}) \mathbf{( n M )}\end{array}$ \\
\hline CCRF-CEM & 371 & 30 \\
\hline HL-60 & 116 & 17 \\
\hline K562 & 506 & 43 \\
\hline MOLT-4 & 277 & 23 \\
\hline RPMI-8226 & 117 & 13 \\
\hline
\end{tabular}

Figure 6. Sensitivity of various leukemia cell lines to 15 - $a z a$-salicylihalamide analogue 2 versus bafilomycin A1 (44). ${ }^{8}$

\section{Migrastatin macrolactam (3)}

Migrastatin (45) is a novel 14-membered macrolide from Streptomyces sp. MK929-43F and is a potent inhibitor of tumor cell migration, invasion and metastasis. ${ }^{7}$ A series of analogs with enhanced tumor cell migration inhibitory properties have been synthesized and their biological activities investigated by in vitro and in vivo studies. Danishefsky and co-workers ${ }^{9,34}$ synthesized the aza migrastatin lactam analogue (3) according to the retrosynthesis in Scheme $\mathbf{6}$ based on their total synthesis of migrastatin. ${ }^{35}$ The key intermediates amine 47 and acid 46 were utilized to generate the macrolactam analogue 3 (Scheme 6) by a diverted total synthesis (DTS) approach. Murphy and co-workers also reported the synthesis of a related aza migrastatin analogue $\mathbf{4 8}$ using a similar synthetic approach. ${ }^{36}$ A $1 \mu \mathrm{M}$ dose of analogue $\mathbf{4 8}$ inhibited migration of gastric cancer cells by up to $50 \%$ in a trans-well cellular locomotion assay.

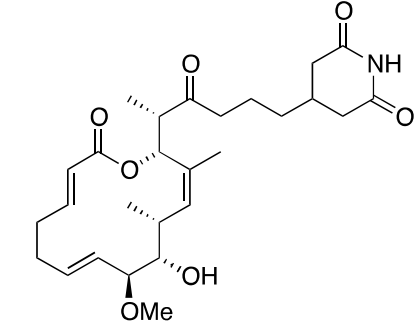

Migrastatin 45 $4 \mathrm{~T} 1$ tumor cells $\mathrm{IC}_{50}=29 \mathrm{mM}$

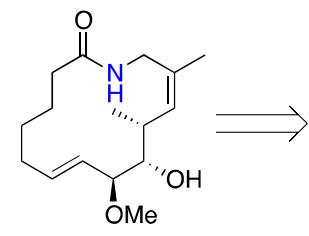

Aza-migrastatin analogue 3

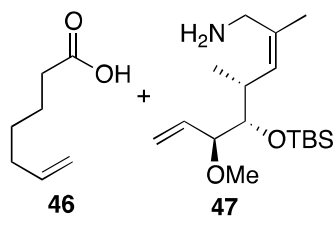

7

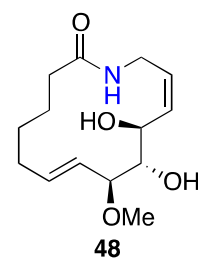

48

Scheme 6. Strategy for the synthesis of aza-migrastatin analogue 3.

A stereoselective hetero-Diels-Alder reaction ${ }^{37}$ between aldehyde $\mathbf{4 9}$ and diene $\mathbf{5 0}$ followed by hydrolysis with TFA gave enone $\mathbf{5 1}$ in good yield as a single diastereoisomer. Reduction and hydrolysis followed by further reduction gave the primary alcohol 52, which was a key intermediate in the total synthesis of migrastatin (45). Selective protection provided an alcohol that was converted into the amine $\mathbf{4 7}$. Coupling with acid $\mathbf{4 6}$ provided diene 53. The synthetic macrolide was prepared by ring closing metathesis of the diene $\mathbf{5 3}$ using Grubbs-II catalyst and deprotection gave the aza-migrastatin analogue 3 which showed better activity against the 4T1 breast cancer cell line than migrastatin (45) $\left(\mathrm{IC}_{50}=0.255 \mu \mathrm{M}\right.$ for 3 vs. $29 \mu \mathrm{M}$ for 45). Mice injected with $4 \mathrm{~T} 1$ cells showed that lactam 3 was also active against human colon tumor LOVO cells $\left(\mathrm{IC}_{50}=0.174 \mu \mathrm{M}\right)$ 
and prostate tumor PC-3 cells $\left(\mathrm{IC}_{50}=1.285 \mu \mathrm{M}\right){ }^{34 \mathrm{~b}}$ In addition, mice implanted with $4 \mathrm{~T} 1$ cells that were injected with $10 \mathrm{mgkg}^{-1}$ of lactam 3 daily had a $91-99 \%$ reduction in the numbers of metastasized 4T1 cells in the lung after 20 days when compared to control mice.

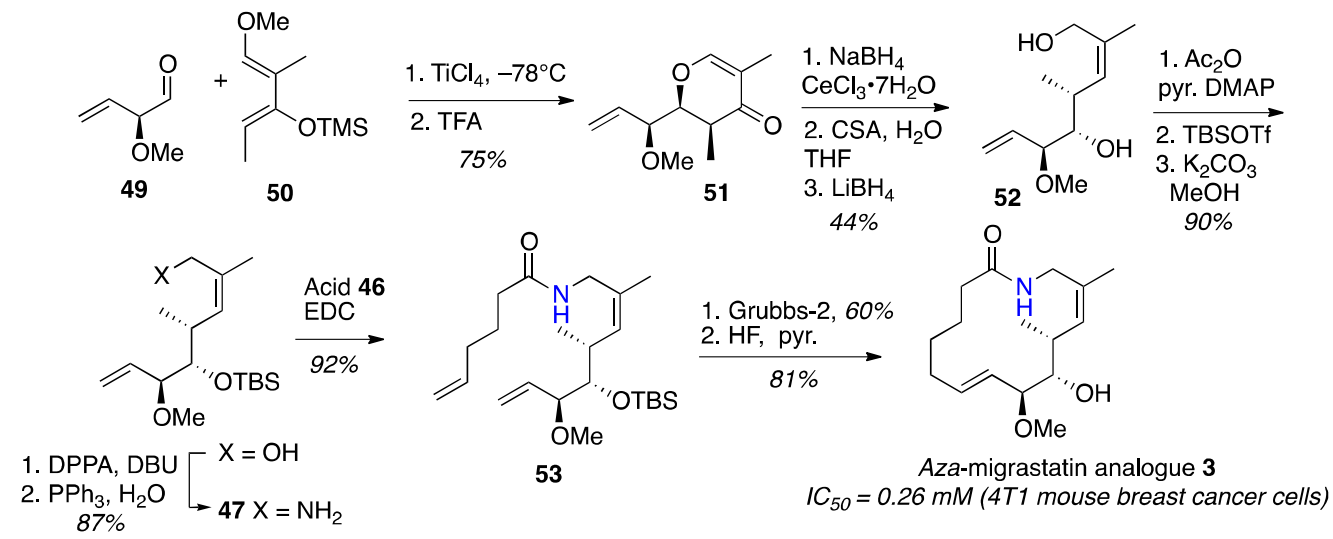

Scheme 7. The synthesis of migrastatin analogue 3 from the migrastatin by a DTS approach. ${ }^{9}$

\section{Radicicol macrolactam analogues}

The essential chaperone heat shock protein 90 (Hsp90) is one of the most common of its type found in eukaryotic cells and captures the energy from ATP-hydrolysis to promote the folding or stabilization of client proteins. Its function and importance has been implicated in diverse diseases including processes in oncogenesis such as self-sufficiency in growth signals. ${ }^{10}$ Hsp90 is an important host factor, promoting several steps of the HIV-1 life cycle, ${ }^{38}$ malaria ${ }^{39}$ and Alzheimer's disease. $^{40,42}$ The overexpression of Hsp90 in tumors by some $2 \sim 10$-fold and its ability to control the stability and activity of oncogenic proteins, makes targeting HSP90 an attractive anticancer strategy. Consequently Hsp90 inhibitors have emerged as a promising therapeutic intervention for a wide variety of human cancers in the past two decades.

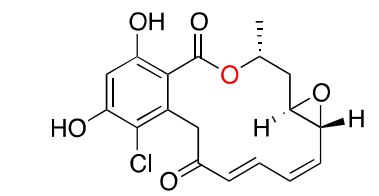

Radicicol 54

TR-FRET IC $C_{50}=0.011 \mu \mathrm{M}$ $F P I C_{50}=0.0043 \mathrm{nM}$ HCT116 SRB GI $50=0.00061 \mu \mathrm{M}$

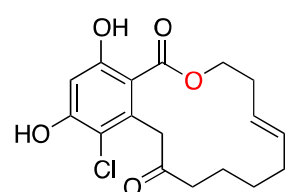

Radicicol analogue 55

TR-FRET IC $C_{50}=0.35 \mu \mathrm{M}$ $F P I C_{50}=0.04 \mathrm{mM}$

HCT116 SRB GI $50=7.6 \mu \mathrm{M}$

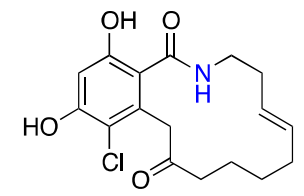

aza-Radicicol analogue 56 TR-FRET IC $C_{50}=0.22 \mu \mathrm{M}$ $F P I C_{50}=0.05 \mu \mathrm{M}$ HCT116 SRB GI $I_{50}=9.6 \mu \mathrm{M}$

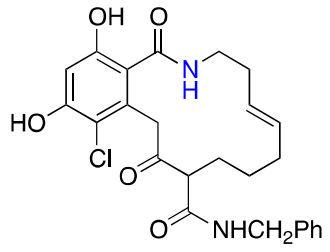

aza-Radicicol analogue 4

TR-FRET $I C_{50}=0.08 \mu \mathrm{M}$

$F P / C_{50}=0.20 \mu M$

HCT116 SRB GI $I_{50}=0.6 \mu \mathrm{M}$

Figure 7. Radicicol (54) the macrolactone analogue 55 and $a z a$ analogues 56 and 4 (TR-FRET and FP assays measure binding of compounds to human Hsp90 $\beta)^{10}$ $\left(\mathrm{GI}_{50}\right.$ against a human colon cancer cell line HCT116) ${ }^{10}$

Radicicol (54) is a 14-membered resorcylic acid lactone macrolide isolated form various fungi ${ }^{41}$ and is a potent in vitro Hsp90 inhibitor $\left(\mathrm{IC}_{50}=20-23 \mathrm{nM}\right.$ ) in cell lines (Figure 7). ${ }^{42}$ However it exhibits no in vivo activity and this may be attributed to its highly reactive epoxide ring, the conjugated dienone system Michael acceptor and the macrolactone, all of which are easily metabolised. Consequently, the challenge has focused on the chemical synthesis of analogues with high activity and metabolic stability and a number of groups have reported the studies towards the synthesis of radicicol lactam analogues. ${ }^{10,43}$ Whilst 12,13 or 16 membered ring radicicol lactone analogues showed reduced activities, ${ }^{44}$ analogues with 14 or 15 -membered rings, including the removal of the diene system, and replacement of the epoxide by a double bond were the most potent Hsp90 inhibitors ${ }^{10}$ (Figure 7). Moody and co-workers reported that the novel macrolactone $\mathbf{5 5}$ and macrolactam analogue $\mathbf{5 6}$ show comparable activity against human colon cancer cell lines. ${ }^{10,43 a}$ The benzylamide analogue $4^{10}$ exhibited at least a 10 -fold higher antiproliferative activity than the 
analogues 55 and $\mathbf{5 6}$ against human colon cancer and was a 4 fold better binder according to TRFRET assays $\left(\mathrm{IC}_{50}=80 \mathrm{nM}\right.$ vs $\mathrm{IC}_{50}=350 \mathrm{nM}$ for $\mathbf{5 5}$ and $\mathrm{IC}_{50}=220 \mathrm{nM}$ for $\left.\mathbf{5 6}\right)$.<smiles>C=CCCCC(OCC)c1cc2c(Cl)c(OC)cc(OC)c2c(=O)oc1=O</smiles>

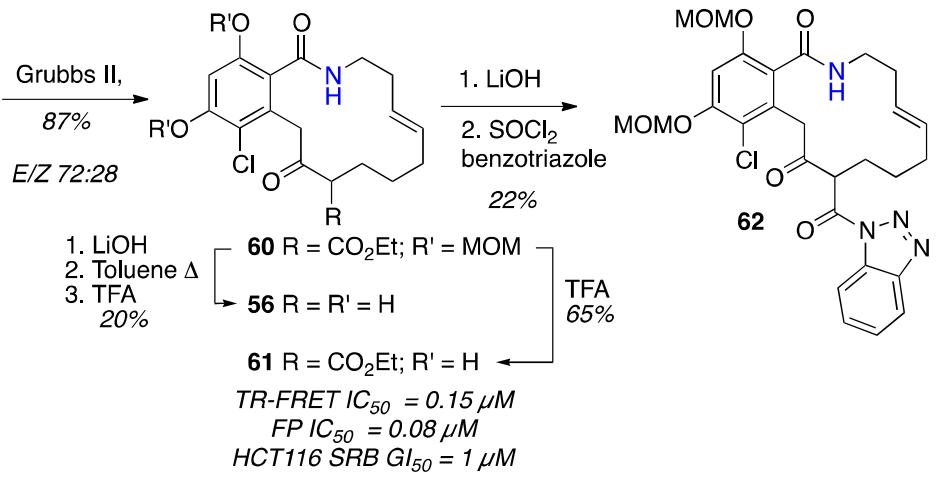
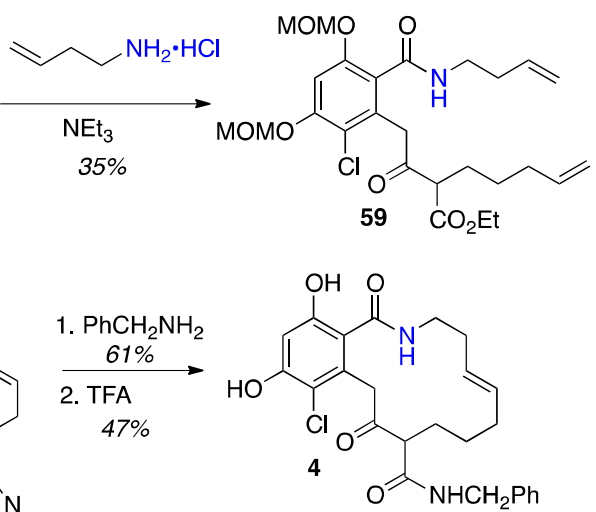

Scheme 8. The synthesis of radicicol lactam analogues 4, 56 and 61.

The synthesis of lactam analogues $\mathbf{4}$ and $\mathbf{5 6}$ is outlined in Scheme 8 and begins with the coupling of 57 and pentenyl malonyl chloride to afford ester 58. Ring-opening with amino-3-butene gave amide 59 which underwent RCM using Grubbs II catalysts to give the $E$-macrolactam $\mathbf{6 0}$ as the major geometric isomer. Hydrolysis followed by decarboxylation and MOM group removal gave the aza-radicicol analogue 56. Alternatively, removal of the MOM ethers from $\mathbf{6 0}$ afforded ester analogue 61 which was a strong binder to Hsp90 and had potent activity against HCT116 comparable to analogue 4. Activation of the ester as the benzotriazole $\mathbf{6 2}$ and displacement with benzyl amine followed by MOM ether removal afforded the $a z a$-radicicol analogue 4. Gratifyingly, macrolactam 56 was metabolically more stable than the lactones with $43 \%$ metabolized by human liver microsomes (after 30 mins) compared to $83 \%$ for radicicol 54, and $90 \%$ for the macrolactone analogue $55 .{ }^{43 a}$
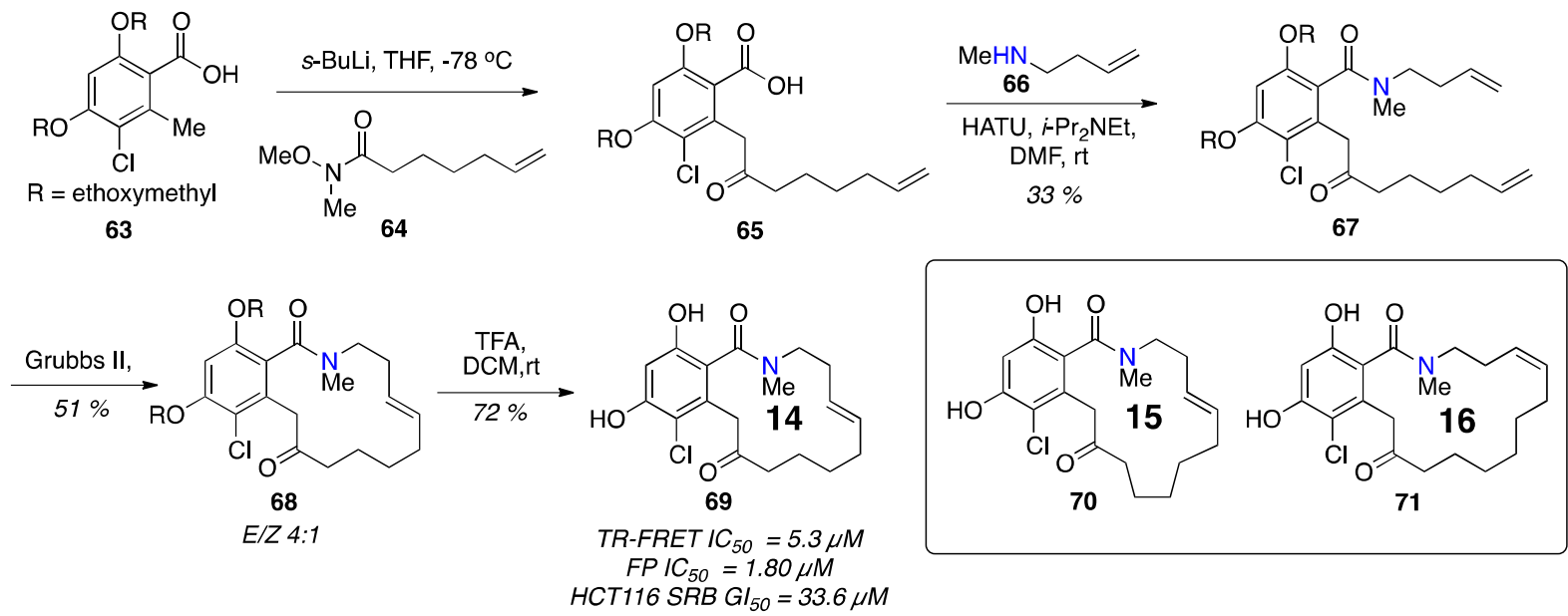
$H C T 116 S R B G I_{50}=33.6 \mu \mathrm{M}$

Scheme 9. The synthetic route to $N$-methyl radicicol macrolactam analogues

A modified synthetic route to generate 14,15 and 16-membered $N$-methyl radicicol macrolactam analogues is outlined in Scheme 9. Benzylic acylation of 63 with Weinreb amide 64 gave ketone 65 but satisfactory reaction yields were achieved only when the acylation reaction was performed at a 
minimum scale of $0.5 \mathrm{mmol}$ of acid $\mathbf{6 3}$ at concentration $0.2 \mathrm{M}$ in THF at -78 . Amide coupling with secondary amine 66 using HATU and Hünig's base provided the diene 67 in $33 \%$ yield. As expected, a mixture of $E / Z$-isomers favoring $E$ isomer $\mathbf{6 8}$ was obtained for the ring closing metathesis of 67 with Grubbs-II. Trifluoroacetic acid deprotection of $\mathbf{6 8}$ provided the $N$-methyl macrolactam 69 with overall yields of up to $12 \%$ from 63. Interestingly, removal of the ethoxymethyl groups from the two phenol groups, then the subsequent RCM was found to appreciably change the $E / Z$-isomer ratios of the macrolactam products. This synthetic strategy was utilized to generate $N$-methyl radicicol 15 and 16-membered ring macrolactam analogues $\mathbf{7 0}$ and $\mathbf{7 1}$. Surprisingly, $N$-methyl lactams 69-71 are much weaker binders to Hsp90 and exhibit greatly reduced potency against HCT116 (Scheme 9). ${ }^{10,43 a}$

\section{Radicicol Lactam Analogues: Binding Studies}

The thermodynamics of binding to Hsp90 $N$-terminal domain showed that although the macrolactams were often better binders than the macrolactone analogues, ${ }^{43 a, 44}$ the natural product radicicol (54) was the best (see Figure 6) implying that the epoxide ring exerts a unique binding and conformational interaction with the Hsp90 backbone that is not replicated by the macrolactams.

Protein X-ray crystallography showed that radicicol $\mathbf{5 4}$ binds to the $N$-terminal domain ATP site of the Hsp90 molecular chaperone with the macrolactone ring in a puckered conformation locked by a key interaction between Lys44 and the epoxide (Figure 8A). ${ }^{45}$ The macrolactone analogue 55 binds to Hsp90 in a very similar manner however without the epoxide there is no interaction with Lys $44{ }^{44}$ This contributes to the fact that lactone $\mathbf{5 5}$ is at least an order of magnitude less effective at binding to Hsp90.

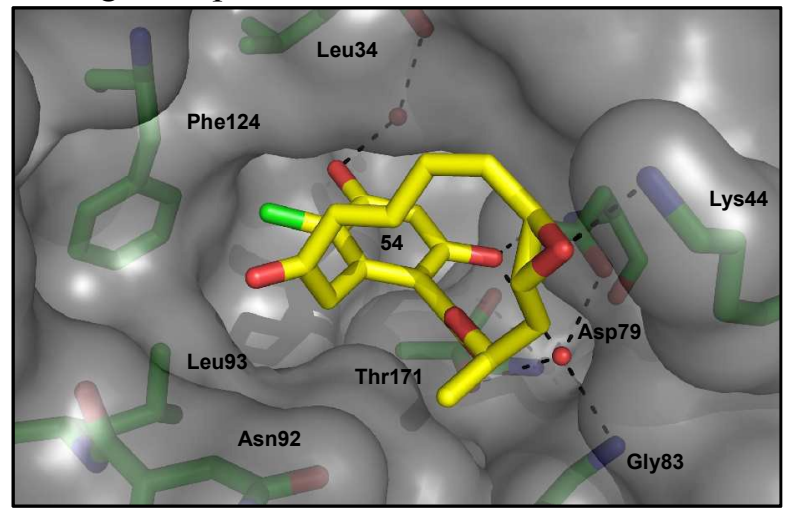

A

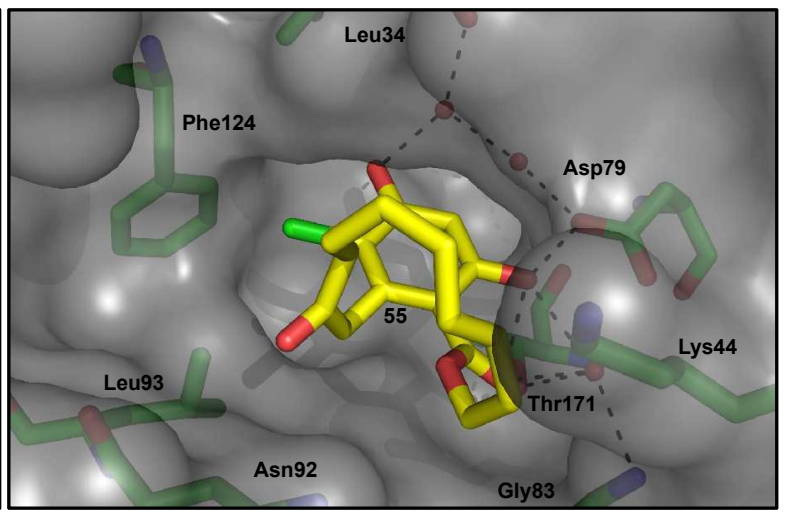

B

Figure 8. (A) Surface map of radicicol (yellow C atoms) 54 bound to $N$-terminal domain of yeast Hsp90 showing key $\mathrm{H}$-bond interactions with water molecules represented by red spheres and H-bonds as black dashed lines (produced from X-ray structure from PDB code 1 bgq see Pearl et. $a .^{45}$ )

(B) Surface map of lactone $\mathbf{5 5}$ bound to Hsp90 showing key interactions (produced from X-ray structure from PDB code 2 cgf see Moody et. al. $^{44}$ )

Moody and co-workers also demonstrated that macrolactams 56 and $\mathbf{4}$ are strong binders to Hsp90 and this was also studied by X-ray crystallographic analysis. ${ }^{10}$ The macrocyclic lactam $\mathbf{5 6}$ binds to Hsp90 with the aromatic ring in the same binding pocket as radicicol (54) and lactone $\mathbf{5 5}$ but with the macrolactam ring more flattened (Figure 9A). Lactam 4 also bound to Hsp90 in a similar manner but with an additional unusual binding of the benzyl amide group via a hydrophobic pocket (lined by residues Met84, Asn92, Leu93, Phe124, Val136, Trp148 and Leu173) and displacing the loop between Leu93 and Lys98 (Figure 9B). ${ }^{10}$ Analogue 4 depletes the representative client Hsp90 proteins C-RAF, ERBB2, and CDK4 and upregulates Hsp72 demonstrating that it acts as a Hsp90 inhibitior in the colon cancer cells assays. Thus, the unusual binding of the $N$ benzylamide in 4 (Figure $8 \mathrm{~B}$ ) to the Hsp90 protein may explain its enhanced biological effects (Figure 7). 


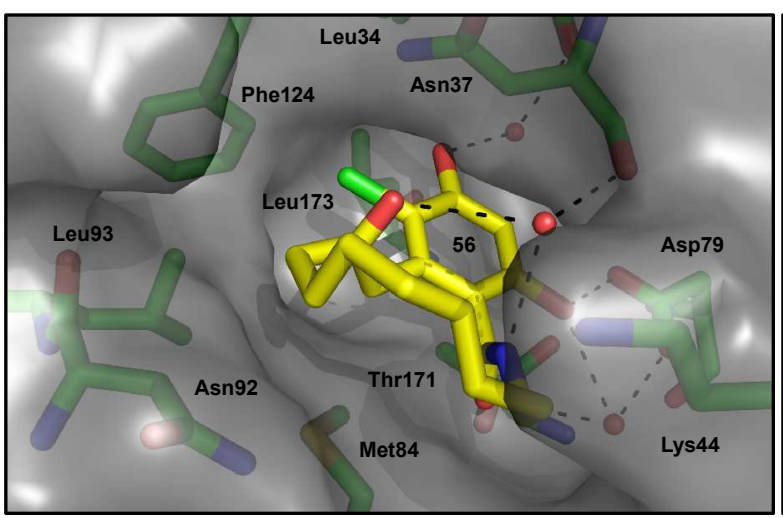

A

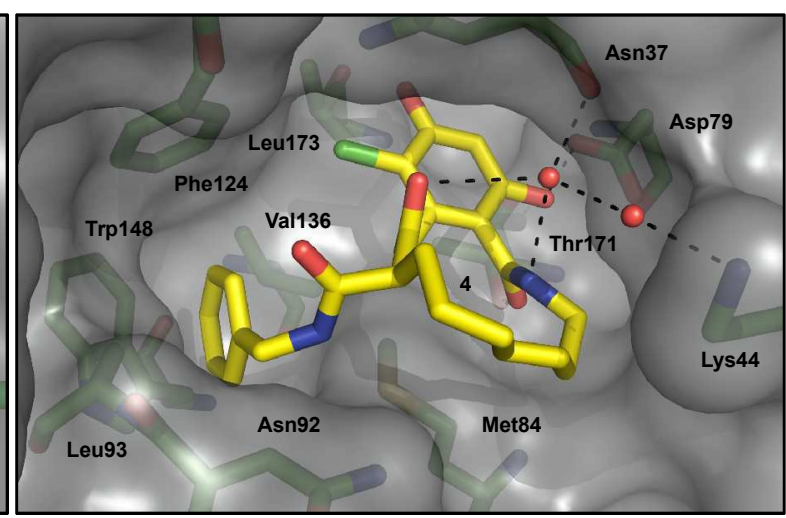

B

Figure 9. (A) Surface map of lactam $\mathbf{5 6}$ bound to Hsp90 showing key interactions (produced from X-ray structure from PDB code $2 \times x 2$ see Moody et. $a .^{10}$ )

(B) Surface map of aza-radicicol analogue 4 bound to Hsp90 showing selected H-bonds and the $N$-benzyl group in the key hydrophobic pocket (produced from X-ray structure from PDB code 2xx5 see Moody et. al..$^{10}$ )

The X-ray structure of lactams $\mathbf{6 1}$ and $\mathbf{7 0}$ bound to Hsp90 (Figure 10) revealed that the key Hbond interactions were similar to those observed for bound lactams $\mathbf{4}$ and $\mathbf{5 6}$ and the macrocyclic ring is again flattened and the ketone carbonyl oriented endo. For lactam 61, the ester group makes additional contacts not observed in lactam 56 (Figure 10A) There is extra H-bonding of the ester via a water molecule to the carbonyl group Phe124 and Asp37. The lactam nitrogen has a contact via water molecule to the ketone carbonyl. For lactam 70, the $N$-methyl group of the lactam nitrogen points out of the binding pocket and the ketone carbonyl is pushed further away, thus explaining the more flattened macrocycle in the bound conformer (Figure 10B). In addition, the lactam $\mathrm{N}$ contacts are not present and this could explain the poor binding of this analogue compared to lactams 4, 56 and 61.

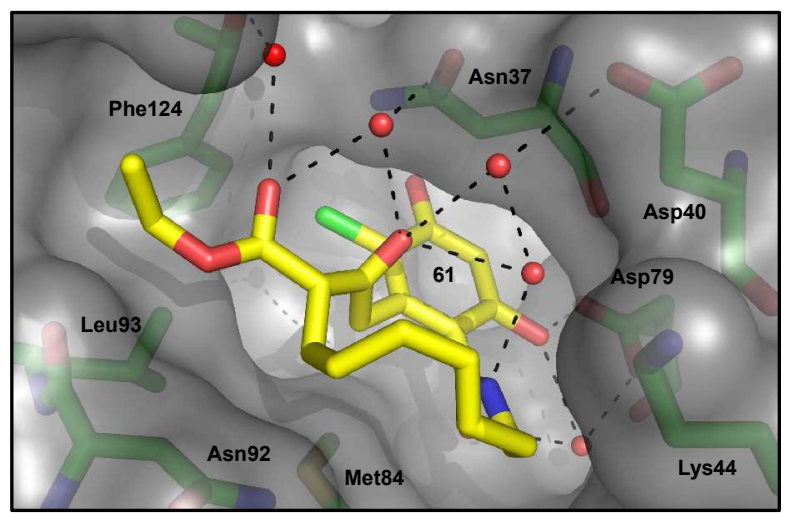

A

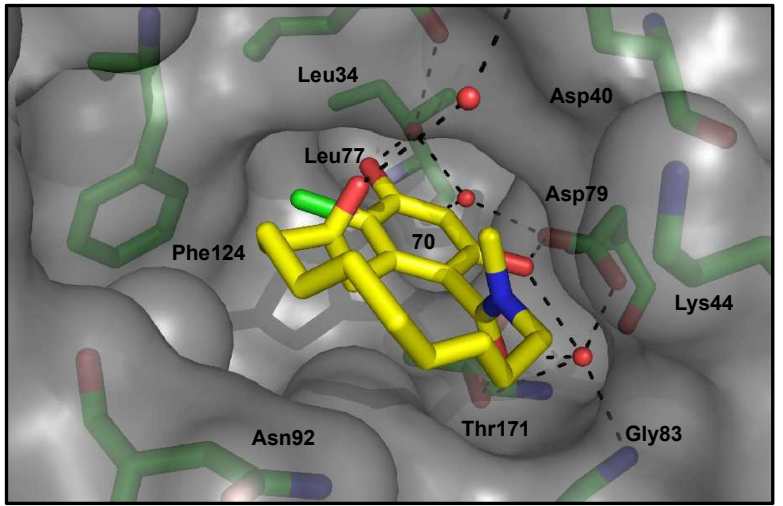

B

Figure 10. (A) Surface map of lactam 61 bound to $N$-terminal domain of yeast Hsp90 showing key interactions. (produced from X-ray structure from PDB code $2 \mathrm{xx} 4$ see Moody et. al. ${ }^{10}$ )

(B) Surface map of lactam $\mathbf{7 0}$ bound to $N$-terminal domain of yeast Hsp90 showing key interactions. (produced from X-ray structure from PDB code 4 ce 2 see Moody et. $a .^{43 a}$ )

As shown in Figure 11A, a comparison of the bound conformations of radicicol (54) and lactone analogue $\mathbf{5 5}$ shows that they are very similar with both in a puckered or 'L-shaped' 46 conformation with the ketone oriented exo. Winssinger and co-workers used molecular dynamics calculations to show that the L-shaped bound conformer of $\mathbf{5 4}$ is the lowest in energy with the flattened or Pshaped conformer higher in energy and an alternative L'-shaped conformer (macrocycle on the opposite side with respect to the benzene ring) the most energetic conformer. ${ }^{46}$ The bound conformer of lactam 56 (Figure 11B) is more P-shaped (planar), with the orientation of the ketone endo. This suggests that that the stronger binding of radicicol 54 can be attributed with the 
macrocycle in a more compact L-shaped conformation. Lactam 4 (Figure 11C) also binds in a similar manner to analogue $\mathbf{5 6}$ with the ketone endo but the extra hydrophobic binding of the benzyl amide increases the binding affinity with the macrolactam ring P-shaped conformation having less effect in this novel binding mode. The last example is lactam $\mathbf{7 0}$ compared to $\mathbf{5 4}$ (Figure 11D) in which the macrolactam ring is the most $\mathrm{P}$-shaped conformation of all the examples presented. This may explain why the $N$-methyl lactam analogues 69-71 are poor binders to Hsp90 compared to the other macrolactams without $N$ methylation. All the bound conformers of the lactam analogues 4, 56, 61 and 70 have the ketone oriented endo and therefore cis to the amide $\mathrm{NH}$ or $N$-methyl group. There are extra H-bonds present for the amide $\mathrm{NH}$ and ketone in binding to Hsp90 which may contribute to their overall better affinity than the lactone $\mathbf{5 5}$, even though this is in a similar conformation as for radicicol (54). Thus, the H-bond to the epoxide in bound radicicol which is not present for $\mathbf{5 5}$ is compensated somewhat by the lactam analogues by interactions involving the lactam nitrogen atom and the ketone carbonyl group.

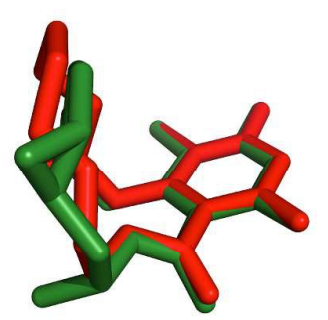

A

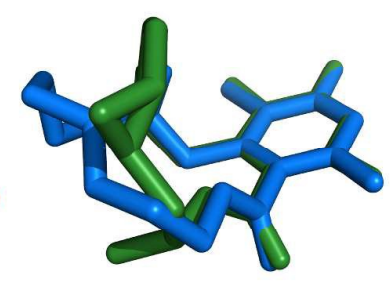

B

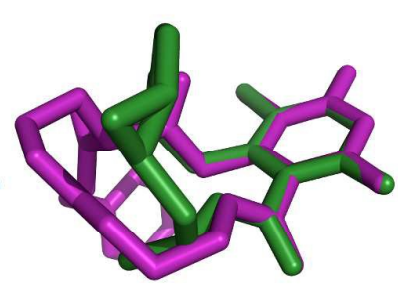

C

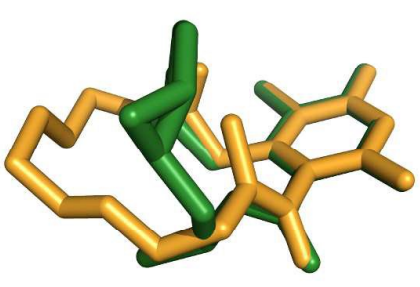

D

Figure 11. Superimposed bound conformations of radicicol 54 (green) (A) with lactone analogue 55 (red),

(B) lactam 56 (blue), (C) lactam 4 (purple) and (D) lactam 70 (orange).

\section{Pochoxime D lactam analogue 74}

The natural product pochonin D (72) is structurally similar to radicicol but does not possess the labile epoxide and was also identified as a good Hsp90 binder by Winssinger et. al (Figure 12). ${ }^{46}$ The oxime analogue $\mathbf{7 3}$ was found to possess better binding affinity for Hsp90 than the natural product 72, possibly due to the fact that the oxime has reduced electrophilicity compared to the ketone, making the oxime analogue a less efficient Michael acceptor and therefore less prone to degradation. ${ }^{46}$

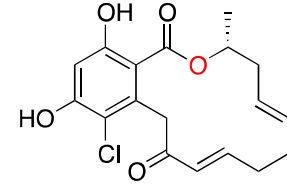

Pochonin D 72

Hsp90 affinity $0.364 \mu \mathrm{M}$

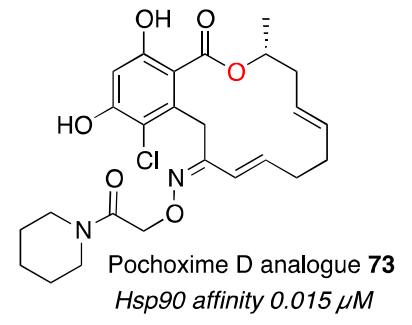

Hsp90 affinity $0.015 \mu \mathrm{M}$

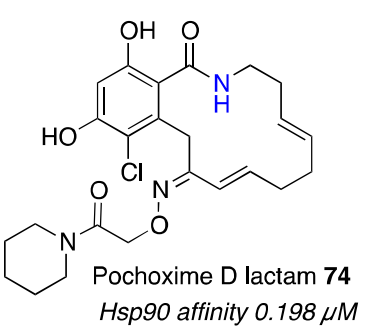

Hsp90 affinity $0.198 \mu \mathrm{M}$

Figure 12. Pochonin D (72) and the macrolactone analogue 73 and $a z a$ analogue 74

Using a solid phase high throughput approach, the macrolactam pochoxime D analogue $\mathbf{7 4}$ was synthesised as outlined in Scheme 10. ${ }^{43 \mathrm{~b}}$ Addition of the benzylic anion derived from $\mathbf{7 5}$ to the Weinreb amide 76 followed by oxime formation gave acid 77. This was attached to solid phase via a chlorotrityl ether linkage and subjected to Tmse group removal with TBAF to afford 78. Coupling of acid 78 with the amine 79 and RCM using Grubbs II catalyst gave macrolactam 80 and cleavage from the linker, amide coupling and ethoxyethyl group removal with solid phase sulfonic acid gave analogue 74. Lactam analogue $\mathbf{7 4}$ was a stonger binder to Hsp90 than pochonin D (72) but a weaker binder ( 5 times less active) compared to the pochonin D analogue $73 .{ }^{47}$ 


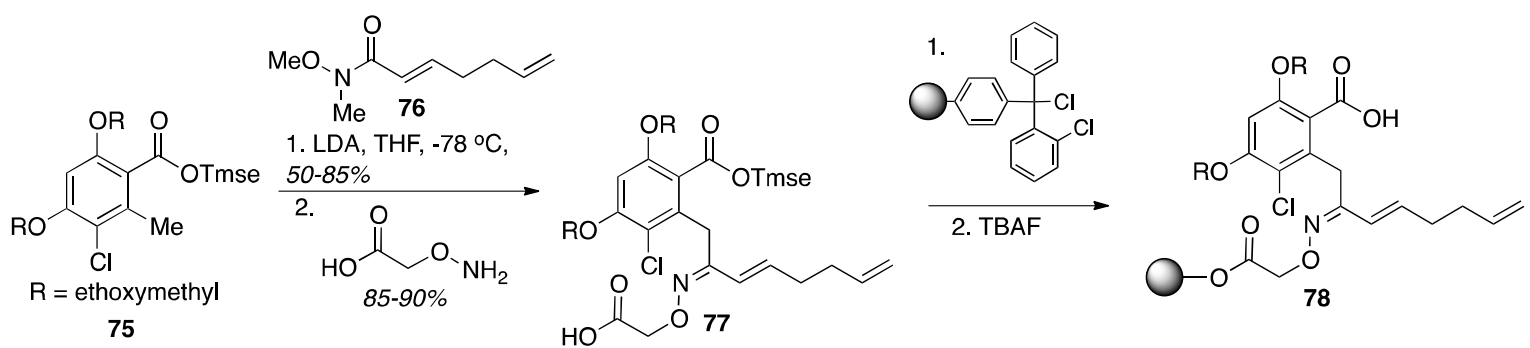
75 HO ${ }^{1}{ }^{1} 77$

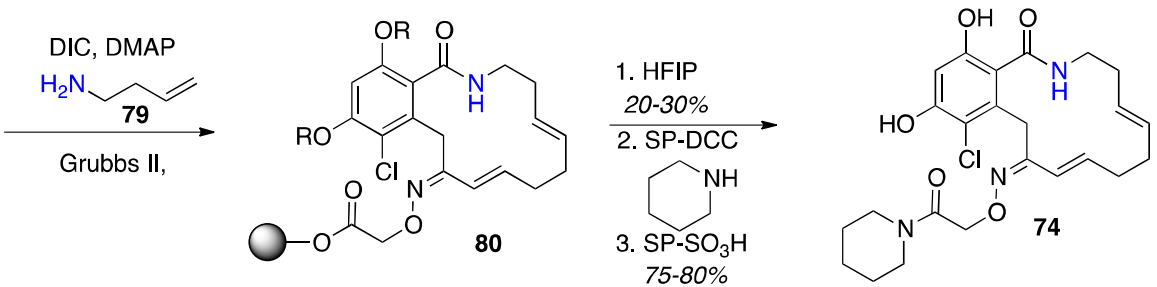

Scheme 10. The synthetic route to macrolactam pochoxime analogue 74 .

Aza derivatives of macrolide antibiotics Antiobiotic macrolide A26771B lactam analogues 76 and 77.

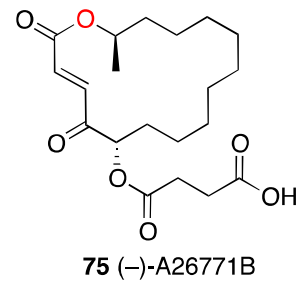

S. aureus MIC $1.56 \mu \mathrm{gmL}^{-1}$<smiles>COCCCCCCCCCCC(C)NC(=O)/C=C\C(=O)OC</smiles>

76<smiles>C/C=C/C(=O)NC(C)CCCCCCCCCC(OC)C(=O)OC</smiles>

77

Figure 13. Antibiotic A26771B (75) and the lactam analogues 76 and 77.

The macrolide (-)-A26771B (75) was isolated from Penicillium turbatum and showed promise as a new class of antibiotic (Figure 13). ${ }^{48}$ Although compound 75 exhibited moderate in vivo activity it was inactive against Staphylococcus aureus and Streptococcus pyogenes infections in mice. This inactivity was attributed to the instability of the macrolactone and succinate half ester and a number of derivatives were synthesized. ${ }^{49}$ The lactam analogues $\mathbf{7 6}$ and $\mathbf{7 7}$ were identified as promising antibiotics and the synthesis of these stereoisomers is shown in Scheme 11.
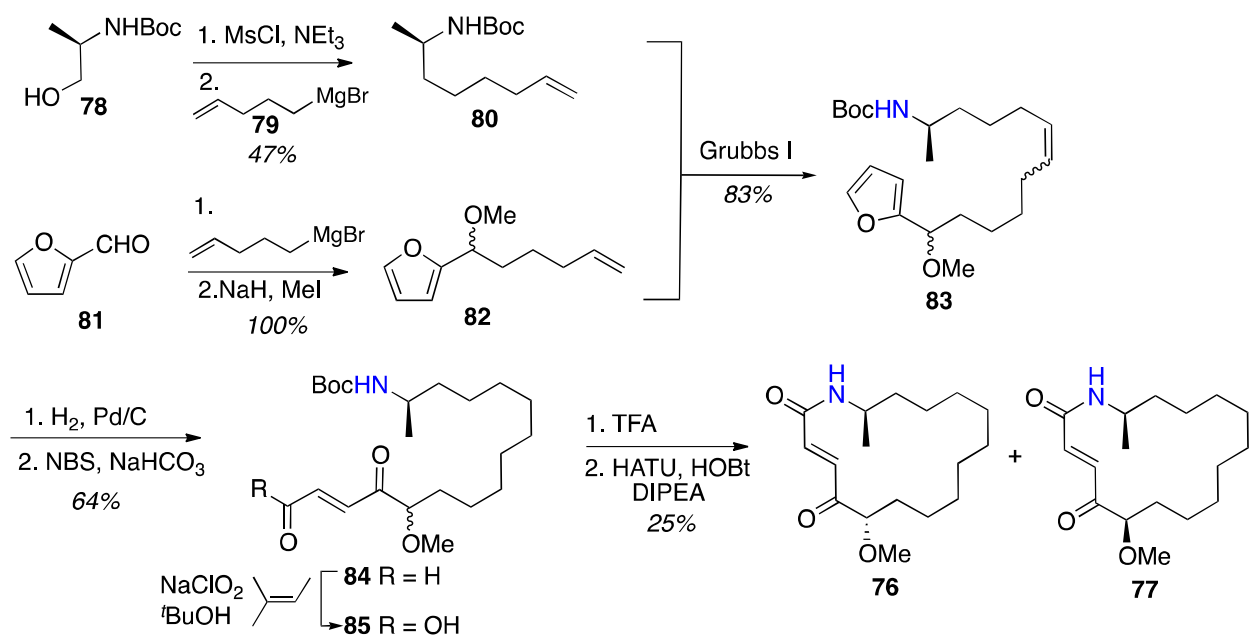

Scheme 11. Synthesis of the A26771B (75) macrolactam analogues 76 and 77. 
Treatment of the mesylate derived from serine derivative $\mathbf{7 8}$ with Grignard reagent $\mathbf{7 9}$ afforded the alkene 80. Addition of the same Grignard reagent to aldehyde $\mathbf{8 1}$ and methylation gave the racemic ether $\mathbf{8 2}$. A cross metathesis between $\mathbf{8 0}$ and $\mathbf{8 2}$ mediated by Grubbs I catalysts gave alkene $\mathbf{8 3}$ as a mixture of four stereoisomers. Hydrogenation followed by oxidative furan ring opening gave aldehyde $\mathbf{8 4}$ which was oxidized to acid $\mathbf{8 5}$. Boc group removal and macrolactamisation gave the lactam diastereoisomers $\mathbf{7 6}$ and $\mathbf{7 7}$ in low yield which were separated by flash chromatography but not fully assigned.

Evaluation of analogues $\mathbf{7 6}$ and $\mathbf{7 7}$ against a panel of bacterial strains showed that they were both essentially identical in their activity and almost always more active than the natural product $\mathbf{7 5}$. Both 76 and 77 had MIC values of $2 \mu \mathrm{gml}^{-1}$ against Enterococcus faecalis whilst A26771B (75) displayed an MIC value of $16 \mu \mathrm{gml}^{-1}$. Analogues $\mathbf{7 6}$ and 77 were also more active than $\mathbf{7 5}$ against strains of Staphylococcus aureus (MIC 1 vs $4 \mu \mathrm{gml}^{-1}$ ), Streptococcus pneumonia (MIC $2 \mu \mathrm{M}$ vs 16 $\mu \mathrm{gml}^{-1}$ ) and Enterococcus faecium (MIC $0.5 \mathrm{vs} 4 \mu \mathrm{gml}^{-1}$ ). More interestingly, 76 and 77 were

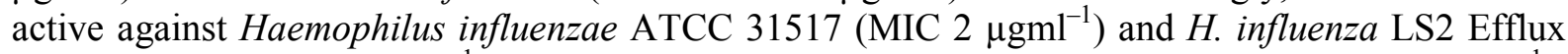
Knock-out (MIC $0.25 \mu \mathrm{gml}^{-1}$ ) whilst the natural product 75 was far less active (MIC $>32 \mu \mathrm{gml}^{-1}$ ). Importantly, The macrolactam analogues remained active in the presence of $10 \%$ human serum in the Staphylococcus aureus assay (MIC $8 \mu \mathrm{gml}^{-1}$ ) while the macrolactone natural product 75 was inactive clearly demonstrating the stability of the macrolactam in human serum. Unfortunately, macrolactams 76 and 77 were orally inactive in a mouse lung infection model at a dose of $50 \mathrm{mgkg}$ 1 .

\section{Glycosylated macrolactam analogues of the macrolide antibiotic $\mathrm{YC}-17$ (87)}

The 14-membered macrolide erythromycin $(\mathbf{8 6})^{50}$ has long been an effective orally active treatment for bacterial infections and many derivatives have also been successful as antibiotics however, the complex nature of these compounds make them difficult to functionalise as macrolactam derivatives (Figure 14). The less complex 12-membered macrolide antibiotic YC-17 (87), isolated from Streptomyces venezuelae ATCC 15439, ${ }^{51}$ was therefore targeted for azaanalogue synthesis and the macrolactam aglycone aza-10-deoxymethynolide (AZDM) (88) was synthesized along with the glycosylated derivatives L-rhamnosyl-AZDM (89) and D-quinovosylAZDM (90) (both produced from $\mathbf{8 8}$ by chemoezymatic synthesis). ${ }^{52}$
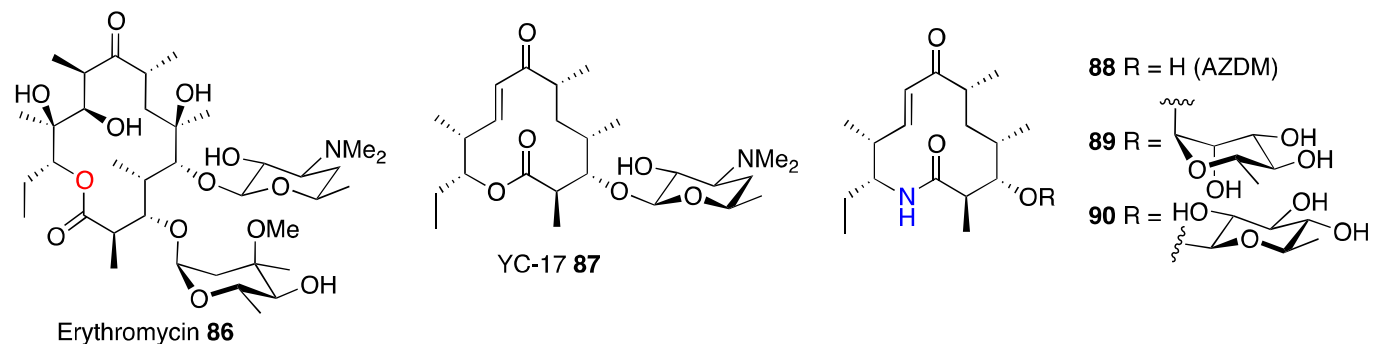

Figure 14. Antibiotics erythromycin (86) and YC-17 (87) and the AZDM (88) glycoside analogues 89 and 90.

The synthesis of AZDM (88) is depicted in Scheme 12 and begins with the coupling of amine 91 with acid $\mathbf{9 2}^{53}$ mediated by $\mathrm{EDC} \cdot \mathrm{HCl}$ and $\mathrm{HOBt}$ to afford amide $\mathbf{9 3}$. Selective primary TBS group removal and oxidation with Dess-Martin periodinane gave the aldehyde 94 which upon treatment with vinyl magnesium bromide and oxidation yielded enone 95. RCM using Grubbs II catalyst gave the macrolactam 96 in good yield as the E-isomer and deprotection gave AZDM (88). Chemoezymatic glycosylation of synthetic $\mathbf{8 8}$ incubation with a mutant strain of $S$. venezuelae YJ028 in which the gene cluster for encoding the pikromycin PKS and desosamine biosynthetic enzymes were deleted (pLRHM2 expressing thymidine diphosphate (TDP) L-rhamnose biosynthetic genes with glycosyltransferase DesVII/DesVIII) afforded low yields of both Lrhamnosyl-AZDM (89) $\left(1.4 \mathrm{mg}\right.$ from $2.4 \mathrm{~L}$ culture) and D-quinovosyl-AZDM (90). ${ }^{52}$ The production of 90 by this process was attributed to the fact that TDP-4-keto-6-deoxy-D-glucose, which is a biosynthetic intermediate of TDP-L-rhamnose, can be reduced with S. venezuelae 4- 
ketoreductase to produce TDP-D-quinovose than then glycosylates AZDM (88). D-QuinovosylAZDM (90) (0.3 mg from $1.8 \mathrm{~L}$ culture) could also be produced by incubation of $\mathbf{8 8}$ with mutant YJ028/pDQNV harboring the D-quinovose biosynthetic genes.
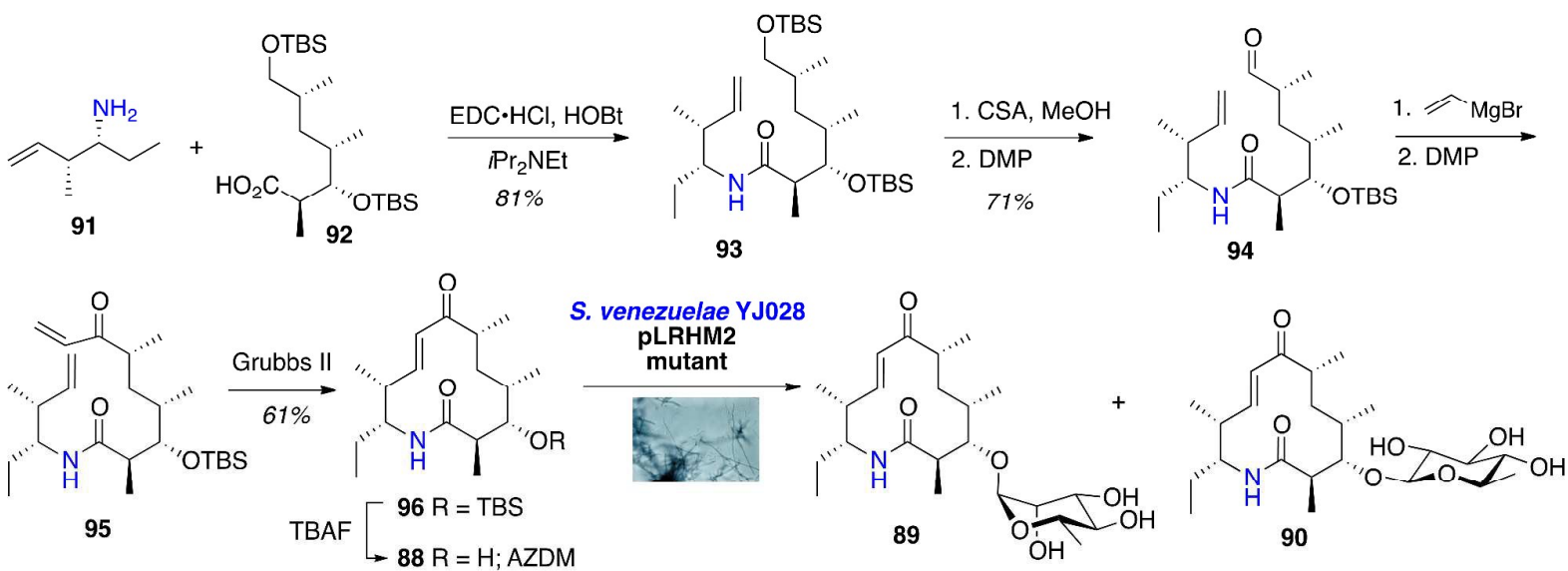

Scheme 12. Synthesis of the ADZM macrolactam glycosides 89 and 90.

Both lactam glycoside analogues 89 and 90 were at least 4 times more active against several bacterial strains in vitro than erythromycin (86) (Table 1). ${ }^{52}$ In addition, the macrolactam 89 was much more stable to the macrolide esterase EreB (isolated from the erythromycin-resistant Escherichia coli) than erythromycin (86). After $1 \mathrm{~h}$ incubation with EreB, erythromycin (86) was completely converted to the linear erthythromycin inactivation product while L-rhamnosyl-AZDM (89) remained intact, even after $24 \mathrm{~h}$ incubation. This clearly shows that the macrolactam analogues of AZDM glycosides are stable to bacterial esterases and are active against erythromycin-resistant pathogens. In addition, macrolactam 89 was shown to be stable on exposure to simulated gastric fluid (SGF). Incubation of erythromycin (86) with SGF resulted in complete degradation to 5desosaminylerythronolide $\mathrm{A}$ in $2 \mathrm{~h}$ but macrolactam $\mathbf{8 9}$ remained intact after incubation with SGF over the same time period. Incubation of erythromycin (86) or macrolactam 89 with rat liver microsomes and NADPH for $2 \mathrm{~h}$ resulted in degradation of the former compound whilst 89 remained unchanged. Finally, both compounds 89 and $\mathbf{9 0}$ showed low cytotoxicity against human cell line HEK293 $\left(\mathrm{IC}_{50}>50 \mu \mathrm{mol}\right)$ making them good candidates for further clinical development.

\begin{tabular}{|c|c|c|c|c|}
\hline \hline Compound & $\begin{array}{c}\text { E. faecium } \\
\text { ATCC19434 }\end{array}$ & $\begin{array}{c}\text { E. faecium } \\
\text { P00558 }\end{array}$ & $\begin{array}{c}\text { S. aureus } \\
\text { ATCC2592 }\end{array}$ & $\begin{array}{c}\text { S. aureus } \\
\text { P00740 }\end{array}$ \\
\hline \hline Erythromycin (86) & 30.0 & $>120.0$ & 60.0 & 120.0 \\
\hline L-Rhamnosyl-AZDM (89) & 7.5 & 30.0 & 15.0 & 30.0 \\
\hline D-Quinovosyl-AZDM (90) & 7.5 & 30.0 & 15.0 & 30.0 \\
\hline
\end{tabular}

Table 1. Antibacterial activities $[\mathrm{MIC}(\mu \mathrm{M})]$ of erythromycin $(\mathbf{8 6})$, L-rhamnosyl-AZDM (89) and D-quinovosyl-AZDM (90).

\section{Conclusion}

The lactam analogue of the myxobacteria metabolite epothilone B (5), namely ixabepilone (1), is the benchmark for $a z a$ modified macrolides. This great success story, starting with the isolation of the natural product, biological assay, SAR and analogue preparation and final clinical application is a key example of how this simple aza modification of macrolides can provide useful active analogues. Inspired by this success, the synthesis of other examples of $a z a$ analogues of macrolide natural products has been pursued by a number of research groups. Macrolactam analogues based on the marine macrolide salicylihalamide (31), bacterial metabolite migrastatin (45), fungal metabolite radicicol (54) and antibiotic macrolides A26771B (75) and YC-17 (87) presented in this review show that significant biological and chemical properties such as metabolic stability, reduced toxicity, protein binding and desirable macrocyclic conformations can be achieved. Thus, the 
modification of the macrolactone to a macrolactam imparts a number of desirable properties apart from derivatives simply being less susceptible to hydrolysis With the further development of efficient synthetic technologies for macrolactam formation, natural product $a z a$ analogues will be even more readily accessible and destined to result in improved therapeutics.

Acknowledgements: We thank the Australian Research Council for financial support.

\section{References}

1. E. Vitaku, D. T. Smith and J. T. Njardarson, J. Med. Chem., 2014, 57, 10257-10274.

2. (a) S. D. Roughley and A. M. Jordan, J. Med. Chem., 2011, 54, 3451-3479; (b) W. P. Walters, J. Green, J. R. Weiss and M. A. Murcko, J. Med. Chem., 2011, 54, 6405-6416.

3. (a) E. Marsault and M.L. Peterson, J. Med. Chem., 2011, 54, 1961-2004; (b) E. M. Driggers, S. P. Hale, J. Lee and N. K. Terrett, Nat. Rev. Drug Discov., 2008, 7, 608-624.

4. E. Comer, J. A. Beaudoin, N. Kato, M. E. Fitzgerald, R. W. Heidebrecht, M. D. Lee, D. Masi, M. Mercier, C. Mulrooney, G. Muncipinto, A. Rowley, K. Crespo-llado, A. E. Serrano, A. K. Lukens, R. C. Wiegand, D. F. Wirth, M. A. Palmer, M. A. Foley, B. Munoz, C. A. Scherer, J. R. Duvall and S. L. Schreiber, J. Med. Chem., 2014, 57, 8496-8502.

5. $\quad$ F. Giordanetto and J. Kihlberg, J. Med. Chem., 2014, 57, 278-295.

6. B. Testa and J. M. Mayer, in Hydrolysis in Drug and Prodrug Metabolism, Ed. B. Testa, Wiley VCH, Zürich, Switzerland, 2003, pp. 163-227.

7. D. M. Bollag, P. A. McQueney, J. Zhu, O. Hensens, L. Koupal, J. Liesch, M. Goetz, E. Lazarides and C. M. Woods, Cancer Res., 1995, 55, 2325-2333.

8. D. Balan, C. J. Burns, N. Fisk, H. Hügel, D. C. S. Huang, D. Segal, C. White, J. Wagler and M. A. Rizzacasa, Org. Biomol. Chem., 2012, 10, 8147-8153.

9. J. T. Njardarson, C. Gaul, D. Shan, X. Y. Huang and S. J. Danishefsky, J. Am. Chem. Soc., 2004, 126, 1038-1040.

10. J. E. H. Day, S. Y. Sharp, M. G. Rowlands, W. Aherene, A. Hayes, F. I. Raynaud, W. Lewis, S. M. Roe, C. Prodromou, I. H. Pearl, P. Workman and C. J. Moody, ACS Chem. Biol., 2011, 6, 1339-1347.

11. (a) G. Höfle, N. Bedorf, H. Steinmetz, D. Schomburg, K. Gerth and H. Reichenbach, Angew. Chem. Int. Ed., 1996, 35, 1567-1569; (b) G. Höfle, N. Glaser, T. Leibold, U. Karama, F. Sasse and H. Steinmetz, Pure Appl. Chem., 2003, 75, 167-178.

12. S. Schneiker, O. Perlova, O. Kaiser, K. Gerth, A. Alici, M. O. Altmeyer, D. Bartels, T. Bekel, S. Beyer, E. Bode, H. B. Bode, C. J. Bolten, J. V. Choudhuri, S. Doss, Y. A. Elnakady, B. Frank, L. Gaigalat, A. Goesmann, C. Groeger, F. Gross, L. Jelsbak, L. Jelsbak, J. Kalinowski, C. Kegler, T. Knauber, S. Konietzny, M. Kopp, L. Krause, D. Krug, B. Linke, T. Mahmud, R. Martinez-Arias, A. C. McHardy, M. Merai, F. Meyer, S. Mormann, J. Muñoz-Dorado, J. Perez, S. Pradella, S. Rachid, G. Raddatz, F. Rosenau, C. Rückert, F. Sasse, M. Scharfe, S. C. Schuster, G. Suen, A. Treuner-Lange, G. J. Velicer, F.-J. Vorhölter, K. J. Weissman, R. D. Welch, S. C. Wenzel, D. E. Whitworth, S. Wilhelm, C. Wittmann, H. Blöcker, A. Pühler and R. Müller, Nature Biotechnology, 2007, 25, 1281-1289.

13. (a) F. Y. F. Lee, R. Borzilleri, C. R. Fairchild, S.-H. Kim, B. H. Long, C. Reventos-Suarez, G. D. Vite, W. C. Rose and R. A. Kramer, Clin. Cancer Res., 2001, 7, 1429-1437; (b) K. H. Altmann and D. Schinzer, in Natural Products in Medicinal Chemistry, Ed. S. Hanessian, Wiley-VCH Verlag GmbH \& Co. KGaA, Weinheim, Germany, 2014, p. 83-125; (c) F. Y. F. Lee, R. Borzilleri, C. R. Fairchild, A. Kamath, R. Smykla, R. Kramer and G. Vite, Cancer Chemother. Pharmacol., 2008, 63, 157-166.

14. J. H. Nettles, H. Li, B. Cornett, J. M. Krahn, J. P. Snyder and K. H. Downing, Science, 2004, 305, 866-869.

15. I. H. Hardt, H. Steinmetz, K. Gerth, F. Sasse, H. Reichenbach and G. Höfle, J. Nat. Prod., 2001, 64, 847-856. 
16. C. R. Harris, S. D. Kuduk, A. Balog, K. Savin, P. W. Glunz and S. J. Danishefsky, J. Am. Chem. Soc., 1999, 7050-7062.

17. C. Aghajanian, H. A. Burris III, S. Jones, D. R. Spriggs, M. B. Cohen, R. Peck, P. Sabbatini, M. L. Hensle, F. A. Greco, J. Dupont and O. A. O'Connor, J. Clin. Oncol., 2007, 25, 10821088.

18. J. T. Hunt, Mol. Cancer Ther., 2009, 8, 275-281.

19. R. M. Borzilleri, X. Zheng, R. J. Schmidt, J. A. Johnson, S. H. Kim, J. D. DiMarco, C. R. Fairchild, J.Z. Gougoutas, F. Y. F. Lee, B. H. Long and G. D. Vite, J. Am. Chem. Soc., 2000, 122, 8890-8897.

20. S. J. Stachel, C. B. Lee, M. Spassova, M. D. Chappell, W. G. Bornmann, S. J. Danishefsky, T. C. Chou and Y. Guan, J. Org. Chem. , 2001, 66, 4369-4378.

21. M. D. Chappell, S. J. StachelC, B. Lee and S. J. Danishefsky, Org. Lett., 2000, 2, $1633-$ 1636.

22. (a) R. Noyori, Tetrahedron, 1994, 50, 4259-4292; (b) D. F. Taber and L. J. Silverberg, Tetrahedron Lett., 1991, 32, 4227-4230; (c) D. F. Taber, L. J. Silverberg and E. D. Robinson, J. Am. Chem. Soc., 1991, 113, 6639-6645.

23. G. L. Gong, Y. Y. Huang, L. L. Liu, X. F. Chen and H. Liu, J. Microbiol. Biotechnol., 2015, 25, 1653-1659.

24. M. Lozynski, J. Phys. Chem. B, 2012, 116, 7605-7617.

25. D. Schinzer, K. H. Altmann, F. Stuhlmann, A. Bauer and M. Wartmann, ChemBioChem, 2000, 1, 67-70.

26. (a) M. R. Boyd, C. Farina, P. Belfiore, S. Gagliardi, J. W. Kim, Y. Hayakawa, J. A. Beutler, T. C. McKee, B. J. Bowman and E. J. Bowman, J. Pharm. Exp. Ther., 2001, 297, 114-120; (b) T. Nishi and M. Forgac, Nature Rev. Mol. Cell Biol., 2002, 3, 94-103.

27. (a) K. L. Erickson, J. A. Beutler, J. H. Cardellina and M. R. Boyd, J. Org. Chem., 1997, 62, 8188-8192; (b) K. L. Erickson, J. A. Beutler, J. H. Cardellina and M. R. Boyd, J. Org. Chem. , 2001, 66, 1532-1532.

28. (a) B. Kunze, R. Jansen, F. Sasse, G. Höfle and H. Reichenbach, J. Antibiot., 1998, 51, 1075; (b) R. Jansen, B. Kunze, H. Reichenbach and G. Höfle, Eur. J. Org. Chem., 2000, 913-919; (c) M. Huss, F. Sasse, B. Kunze, R. Jansen, H. Steinmetz, G. Ingenhorst, A. Zeeck and H. Wieczorek, BMC Biochem., 2005, 6, 13-21.

29. (a) S. Wilkens, T. Inoue and M. Forgac, J. Biol. Chem., 2004, 279, 41942-41949; (b) H. Reichenbach, J. Ind. Microbiol. Biotechnol. , 2001, 27, 149-156.

30. A. B. Smith III and J. Zheng, Tetrahedron, 2002, 58, 6455-6471.

31. O. Soltani and J. K. De Brabander, Angew. Chem., Int. Ed., 2005, 44, 1696-1699.

32. L. Jiang, G. E. Job and S. L. Buchwald, Org. Lett., 2003, 5, 3667-3669.

33. E. J. Bowman, A. Siebers and K. Altendorf, Proc. Natl. Acad. Sci. U. S. A., 1988, 85, 79727976.

34. (a) D. Shan, L. Chen, J. T. Njardarson, C. Gaul, X. Ma, S. J. Danishefsky and X. Y. Huang, Proc. Nat. Acad., Sci. USA, 2005, 102, 3772-3776; (b) N. Lecomte, J. T. Njardarson, P. Nagorny, G. Yang, R. Downey, O. Ouerfelli, M. A. S. Moore and S. J. Danishefsky, Proc. Nat. Acad. Sci., USA, 2011, 15074-15078; (c) T. Oskarsson, P. Nagorny, I. J. Krauss, L. Perez, M. Mandal, G. Yang, O. Ouerfelli, D. Xiao, M. A. Moore, J. Massague and S. J. Danishefsky, J. Am. Chem. Soc., 2010, 132, 3224-3228.

35. C. Gaul, J. T. Njardarson and S. J. Danishefsky, J. Am. Chem. Soc., 2003, 125, 6042-6043.

36. G. Anquetin, G. Horgan, S. Rawe, D. Murray, A. Madden, P. MacMathuna, P. Doran and P. V. Murphy, Eur. J. Org. Chem., 2008, 2008, 1953-1958.

37. S. J. Danishefsky, Aldrichimica Acta 1986, 19, 59-69.

38. J. S. Low and A. Fassati, Parasitology, 2014, 141, 1192-1202.

39. A. G. Bavih and D. R. Pillai, Parasitology, 2014, 141, 1216-1222.

40. V. Calabrese, G. Scapagnini, C. Colombrita, A. Ravagna, G. Pennisi, G. A. M. Stella, F. Galli and D. A. Butterfield, Amino Acids, 2003, 437-443. 
41. (a) P. Delmotte and J. Delmotteplaquee, Nature, 1953, 171, 344; (b) R. N. Mirrington, E. Ritchie, C. W. Shoppee, W. C. Taylor and S. Sternhell, Tetrahedron Lett., 1964, 7, 365370 .

42. (a) M. Wang, G. Shen and B. S. J. Blagg, Bioorg. Med. Chem. Lett., 2006, 16, 2459-2462; (b) S. H. Kim, J. G. Kang, C. S. Kim, S. H. Ihm, M. G. Choi, H. j. Yoo and S. J. Lee, Anticancer Res., 2014, 34, 4829-4837.

43. (a) B. I. Dutton, R. R. A. Kitson, S. Parry-Morris, S. M. Roe, C. Prodromou and C. J. Moody, Org. Biomol. Chem., 2014, 12, 1328-1340; (b) S. Barluenga, J.-G. Fontaine, C. Wang, K. Aouadi, R. Chen, K. Beebe, L. Neckers and N. Winssinger, ChemBioChem, 2009, 10, 2753-2759; (c) Z.-Q. Yang, X. Geng, D. Solit, C. A. Pratilas, N. Rosen and S. J. Danishefsky, J. Am. Chem. Soc., 2004, 126, 7881-7889.

44. N. Proisy, S. Y. Sharp, K. Boxall, S. Connelly, S. M. Roe, C. Prodromou, A. M. Z. Slawin, L. H. Pearl and C. J. Moody, Chem. Biol. , 2006, 13, 1203-1215.

45. S. M. Roe, C. Prodromou, R. O'Brien, J. E. Ladbury, P. W. Piper and L. H. Pearl, J. Med. Chem., 1999, 42, 260-266.

46. E. Moulin, V. Zoete, S. Barluenga, M. Karplus and N. Winssinger, J. Am. Chem. Soc., 2005, 127, 6999-7004.

47. S. Barluenga, C. Wang, J.-G. Fontaine, K. Aouadi, K. Beebe, S. Tsutsumi, L. Neckers and N. Winssinger, Angew. Chem. Int. Ed., 2008, 47, 4432-4435.

48. K. H. Michel, P. V. Demarco and R. Nagarajan, J. Antibiot., 1977, 30, 571-575.

49. S. Canova, R. Lépine, A. Thys, A. Baron and D. Roche, Bioorg. Med. Chem. Lett., 2011, 21, 4768-4772.

50. J. M. McGuire, P. L. Bunch, R. C. Anderson, H. E. Boaz, E. H. Flynn, E. H. Powell and J. W. Smith, Antibiot. Chemother., 1952, 2, 281-283.

51. A. Kinumaki and M. Suzuki, J. Chem. Soc., Chem. Commun., 1972, 744-745.

52. P. B. Shinde, H.-S. Oh, H. Choi, K. Rathwell, Y. H. Ban, E. J. Kim, I. Yang, D. G. Lee, D. H. Sherman, H.-Y. Kang and Y. J. Yoon, Adv. Synth. Cat., 2015, 357, 2697-2711.

53. A.-R. Shareef, D. H. Sherman and J. Montgomery, Chem. Sci., 2012, 3, 892-895. 